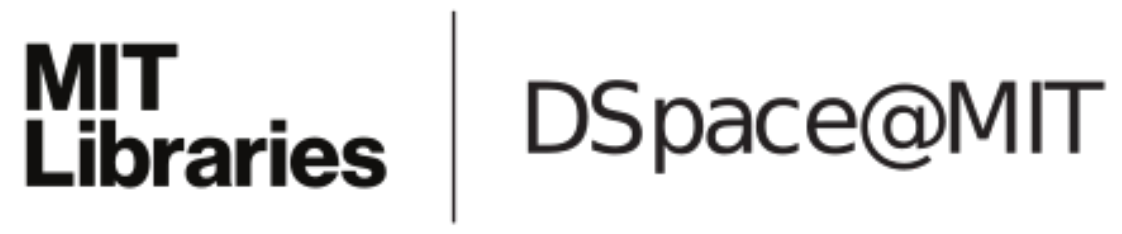

\author{
MIT Open Access Articles
}

Banking integration and house price co-movement

The MIT Faculty has made this article openly available. Please share how this access benefits you. Your story matters.

Citation: Landier, Augustin et al. "Banking integration and house price co-movement." Journal of Financial Economics 125, 1 (July 2017): 1-25 (C) 2017 Elsevier

As Published: http://dx.doi.org/10.1016/j.jfineco.2017.03.001

Publisher: Elsevier BV

Persistent URL: https://hdl.handle.net/1721.1/122351

Version: Author's final manuscript: final author's manuscript post peer review, without publisher's formatting or copy editing

Terms of use: Creative Commons Attribution-NonCommercial-NoDerivs License 


\title{
Banking Integration and House Price Comovement*
}

\author{
Augustin Landier ${ }^{\dagger} \quad$ David Sraer ${ }^{\ddagger} \quad$ David Thesmar ${ }^{\S}$
}

February 9, 2016

\begin{abstract}
The correlation across US states in house price growth increased steadily between 1976 and 2000. This paper shows that the contemporaneous geographic integration of the US banking market, via the emergence of large banks, was a primary driver of this phenomenon. To this end, we first theoretically derive an appropriate measure of banking integration across state pairs and document that house price growth correlation is strongly related to this measure of financial integration. Our IV estimates suggest that banking integration can explain up to one fourth of the rise in house price correlation over this period.
\end{abstract}

${ }^{*}$ We thank Evren Ors and Tomasz Michalski for numerous conversations and for providing us with their deregulation data. We are also thankful to Prasad Krishnamurthy for sharing his deposit data with us. For helpful comments, we are grateful to an anoymous referee, Toni Whited, Xavier Gabaix, Valentin Haddad, Jakub Jurek, Holger Mueller, as well as seminar participants at the Swiss Banking Conference, Berkeley Haas, UvA, Erasmus, NYU Stern, HBS, University of Michigan, the IMF, the New York FED, Duke FUQA, Sciences Po, UBC, and Tilburg. Charles Boissel provided excellent research assitance. All remaining errors are our own.

${ }^{\dagger}$ Toulouse School of Economics (e-mail: augustin.landier@tse-eu.fr)

${ }^{\ddagger}$ UC Berkeley and NBER and CEPR (e-mail: sraer@berkeley.edu)

${ }^{\S} \mathrm{HEC}$ and CEPR (e-mail: thesmar@hec.fr) 
"Judging from the historical record, a nationwide drop in real housing prices is unlikely, and the drops in different cities are not likely to be synchronous: some will probably not occur for a number of years. Such a lack of synchrony would blunt the impact on the aggregate economy of the bursting of housing bubbles." (?)

\section{Introduction}

House prices across US states became increasingly correlated throughout the 1980s and the 1990s. Over the five years following 1976, the median five-year forward correlation of house price growth across state pairs was $11 \%$; one third of the state pairs had negatively correlated house prices. Over the five years following 1999, the median correlation reached 35\%; the fraction of negatively correlated state pairs decreased to 15\%. As shown in Figure 1, house price synchronization has increased continuously over the past three decades. This fact is confirmed in several studies, which use different data or periods, but all find evidence of an increasing comovement in U.S. house prices. (????). ${ }^{1}$ During the same period, the US banking market has become increasingly integrated, through consecutive waves of deregulations that took place between the late 1970s and the mid-1990s (?). One of the contributions of the paper is to show that these two phenomena are related: Increasing bank integration explains a sizable part of the rise in house price comovement.

The objective of this paper is to document the causal impact of financial integration on house price correlation. We build on the large literature on internal capital markets in banks, which documents that funding shocks to a bank holding company tend to propagate to its divisions, and affect their lending (see, e.g., ?, ?, ?, ?). Through these internal capital

\footnotetext{
${ }^{1}$ Our paper is the first one, to our knowledge, to document this long-term trend on US states, using OFHEO data since 1976. But quite a few papers have already provided evidence of the increase in house price correlation. Using the same data, but on the 2000s only, ? have documented an increase in house price correlation across US cities during the real estate boom. Using Case \& Shiller data for 10 large cities, ? have also documented an increase in house price correlation in recent years. Finally, ? have shown a long-term increase in international house prices. On a different note, ? show that over the same period, the dispersion of house prices levels across US cities has also gone up. This finding is not inconsistent with the fact we document here: prices co-vary more (our paper), but their levels differ more (theirs).
} 
markets, a bank simultaneously operating in several states creates a commonality in lending across these states, which, in turn, synchronizes house price movements to the extent that bank lending affects house prices (?, ?, ?). Empirically establishing the causality from bank integration to house price growth correlation is more challenging. To address this challenge, we proceed in two steps.

First, we develop a simple statistical model that explicitly connects bank integration to house price growth correlation. We use this model to derive an empirically testable relationship between house price growth correlations and a relevant measure of bank integration. This measure captures the extent to which large banks overlap across a given pair of states. Formally, for each state pair $(i, j)$, it is defined as the sum, taken across all banks operating in both states, of the products of their market shares in each state. The market shares are defined as the fraction of real estate loans held by the bank in the state relative to the state total real estate lending. ${ }^{2}$

The model also delivers two key insights that shed new light on the link between bank integration and asset price comovement. First, the link between financial integration and house price correlation goes through idiosyncratic bank lending shocks. If lending is only affected by aggregate shocks (e.g., because all banks securitize or rely on wholesale funding), banking integration has no effect on house price comovement: aggregate shocks affect all banks the same way, whether they operate in a single or in multiple markets. However, when banks face idiosyncratic lending shocks and operate in multiple states, their lending activity induces house price comovement. For idiosyncratic shocks to matter, however, the market needs to be sufficiently concentrated. This observation leads to the second insight of the model: bank integration only matters to the extent that banks operating across states are large enough in each state. If banking markets become more integrated but banks remain small, the law of large number will smooth out the impact of idiosyncratic shocks, and

\footnotetext{
${ }^{2}$ This co-Herfindhal measure thus ranges from 0 when the two states are completely segmented - no common lending between the two states or market shares of each banks operating in both states close to 0 to 1 when the two states are perfectly integrated - a single bank responsible for the whole lending activity in both states.
} 
integration will have no effect on house price growth correlation. Put simply, "granularity" is a necessary ingredient for banking integration to induce comovement in house prices. Our integration measure embodies both insights.

Second, we use interstate banking deregulations as shocks to banking integration across US state pairs, in order to establish that financial integration causally affects the comovement of house prices. We exploit the fact that these deregulations were essentially bilateral and staggered between 1978 and 1994. Consistent with the findings in ?, we find that these bilateral interstate banking deregulations had a strong and immediate impact on our measure of financial integration ${ }^{3}$ We then show that these deregulations were immediately followed by a sharp increase in house price correlation (about 8 percentage points on average across specifications). Finally, we use these deregulations as instruments for banking market integration. This IV estimate allows us to quantify the effect of integration on house price comovement. We defend the validity of these deregulations as instruments for banking integration at length in Section 4.1. Using these instruments, we then find an economically and statistically significant relationship from bank integration to house price correlation across state pairs. This relationship resists a battery of robustness checks. We finally use our crosssectional estimate to shed light on the time-series rise in house price comovement which we described at the beginning of this paper. Given our cross-sectional estimates, we attribute as much as one fourth of the increase in house price correlation over the 1976-1995 period to the rise in banking integration, which, as we show, mostly took place through the expansion of the 20 largest Bank Holding Companies (BHC) across state boundaries. So the rise in house price comovement is directly connected to the rising granularity of the U.S. banking market.

This paper contributes to three strands of the literature. First, we contribute to the broad literature on capital flows and contagion. The international finance literature documents increasing comovement in equity prices since the 1970s (see ? for a summary and

\footnotetext{
${ }^{3}$ See also ? for the use of these deregulations in a different context
} 
new evidence from global equity markets). Such comovement is typically interpreted as a consequence of capital market integration. When capital can flow more freely across borders, asset prices become more sensitive to shifts in global investor demand. In line with this interpretation, several papers have reported significant cross-sectional relationships between asset prices correlation and the intensity of capital flows between countries. ${ }^{4}$ Within this literature, our paper offers new, causal, evidence for a new asset class (real estate) for states that experienced a drastic integration of capital markets in an otherwise fairly homogeneous economy. Such integration occurred via the banking market and was driven primarily by bilateral, staggered, deregulations. These policy experiments in the context of otherwise relatively homogenous states, allow us to isolate the causal impact of capital (banking) flows on asset price comovement. ${ }^{5}$

Second, we contribute to the literature in economics and finance that seeks to explain aggregate fluctuations with shocks to very large firms. ? shows that idiosyncratic shocks to large firms have the power to explain aggregate volatility. The evidence on such "granular origins of aggregate fluctuations" is, however, mixed. On the one hand, ? find no role for idiosyncratic volatility in explaining the volatility of US manufacturing output. On the other hand, ? find that banking concentration in Japan is large enough to give a significant role to idiosyncratic shocks on aggregate lending volatility. ? also show that the concentration of customer networks is an important determinant of firm-level volatility and that at the macro level, the firm-volatility distribution is driven by firm-size dispersion. Whereas these papers focus on volatility, our study emphasizes the "granular origins of comovement". Our statistical model shows that financial integration can only affect asset price comovement via large banks. In the data, the increase in banking integration - which causes correlation is mostly driven by the 20 largest banks. Hence, taken together with the above papers,

\footnotetext{
${ }^{4}$ In line with this literature, ? show that asset price correlation was large in the beginning of the $20^{t h}$ century and decreased substantially before WWII. ? provide evidence that many asset classes have become more correlated over time. But they link this evolution to macro shocks, not to credit supply.

${ }^{5}$ This paper also relates to the literature on the effects of financial integration on GDP fluctuations and synchronisation (?, ?). Compared to these papers, we exploit truly bilateral deregulations; and focus on house prices, which are directly to banking activity via mortgage lending, instead of real activity
} 
our results suggest that idiosyncratic credit supply shocks are an important contributor to aggregate shocks.

Finally, we add to the body of evidence that credit supply affects housing prices. The presence of such a relationship is a priori not obvious theoretically and is hard to identify in the data without a proper instrument (?). A series of recent papers have used sophisticated identification strategies to isolate the impact of credit-supply shocks on house prices. These papers have used instruments related to securitization demand by GSEs (?, ?) or branching deregulations (?). Our paper complements this literature by using an alternative instrument (pairwise interstate banking deregulations) and by focusing on the time-series and cross-sectional properties of house price growth correlation across US states. Housing price comovement is interesting in its own right given that it is a key component of the pricing of CDO tranches. Underestimating this correlation -as in the opening quote of this paper- may have led to underestimating the risk of junior CDO tranches in the pre-crisis period (?).

Section 2 describes the data and documents the strong increase in house price comovement over the past three decades. Section 3 lays out a simple statistical model that highlights the role of financial integration on house price correlation and documents the rise in bank integration in the United States over the 1976-1995 period. Section 4 goes back to the data and shows the causal impact of bank integration on house price correlation in the cross section of state pairs. Section 5 concludes.

\section{Data}

\subsection{Data Construction}

Our dataset is the balanced panel of all US state pairs from 1976 to 2000. It contains measures of house price comovement, personal income comovement, state-pair proximity in industry composition, and a measure of state-pair banking integration. To compute these 
variables, we use four sources of data: quarterly state-level house price index from OFHEO, state-level bank lending from the Call Reports, state-level bank deposits from the FDIC Summary of Deposits data and state-level labor income from the BLS.

\subsubsection{House Prices}

We retrieve state-level, repeated-sales, house price indices from the OFHEO website for the period ranging from 1976 to 2000. These data are available quarterly for all US states since 1976. We stop in 2000 because our IV strategy is based on deregulations happening between the mid 1980s and 1995. As we will see below, call reports also impose a constraint on our time frame. We use these data to calculate quarterly residential real estate price growth. Two considerations drive our focus on state-level data (as opposed to MSA level data): (1) our instrument - interstate banking deregulation - is defined at the state-pair level and (2) the OFHEO data cover all states since 1976, but its coverage of MSA-level prices is complete only after 1994 .

For each state pair, we use these data to compute the time series of house price growth correlation. More precisely, for each state pair and each year, we compute the correlation of house price growth in each state of the pair, over the next 20 quarters (including the four quarters of the current year). To ensure our results are not influenced by seasonality in house prices, we also compute the correlation of house price growth after adjusting house price growth for seasonality. Precisely, we regress each state-level house price growth time series on quarter dummies and use the residual as our seasonally-adjusted measure of house price growth. These two measures of correlation, raw and seasonally-adjusted, will be our main measures of house price comovement, but we also show robustness with three additional measures. First, we compute house price growth correlation over a 12-quarter rolling window. This alternative proxy is noisier but more responsive to regime changes. Second, using a 20-quarter rolling window, we also compute the covariance of house price growth across state pairs. Third, we compute the "beta" of house price growth in state $i$ with respect to 
house price growth in $j(?)$. More accurately, for each state-pair $(i, j), \beta^{i j}$ is the regression coefficient of house price growth in state $i$ on house price growth in state $j$, taking the next 20 quarters as the estimation sample.

Table I reports summary statistics for these comovement measures, for each one of the $50 \times 51 / 2-50=1,225$ state pairs between 1976 and 1996 (these statistics stop in 1996 because of the 5-year forward rolling window used to compute these statistics). The sample has $21 \times 1225=25,725$ observations. The average house price growth correlation over a five year horizon is .185 , with a median of .188. The correlation over a three year horizon is similar, with a mean of .195 and a median of .207 . Less than $30 \%$ of the observations have negative house price growth correlation. Section 2.2 discusses the summary statistics of correlation as well as the trends in correlation in detail.

\subsubsection{Geographic Dispersion of Banks}

To compute our measure of bank integration at the state-pair level, we need to observe a measure of bank lending at the state level. We consider two different measures. First, we use the call reports consolidated at the BHC level, from 1976 to 2000. These data are available quarterly and provide us, for each commercial bank, with its identification number (rssd9001), its total real estate loans (rcfd1410), its state of location (rssd9200), and the BHC with which it is affiliated (rssd9348) - provided one exists. We then collapse real estate loans, each quarter, at the BHC-state level. For instance, if a BHC owns two commercial banks in Arizona (with real estate loans of $\$ 3 \mathrm{bn}$ and $\$ 5 \mathrm{bn}$ ), we say its total lending in this state is $\$ 8 \mathrm{bn}$. When a commercial bank is independent, we keep the observation —as if the commercial bank were a BHC owning itself.

By performing this aggregation, we implicitly assume commercial banks do not operate outside the borders of the state where they are located. This assumption is a good approximation until the Riegle-Neal Act of 1994, which allowed BHCs to consolidate activities in several states into a single commercial bank (?). After 1994, bank asset location information 
becomes noisier as larger banks progressively consolidate loans across state borders. With this shortcoming in mind, we choose to use the call reports data until 2000 in our main regressions. We do, however, systematically provide robustness checks for 1976-1994 only, to ensure that potential biases induced by the Riegle-Neal Act do not affect our findings. As we will see, they do not.

Our second proxy for bank-lending at the state level comes from the FDIC Summary of Deposits. The data provides us over the sample period with total deposits held by each commercial bank at the county level. We aggregate the data at the state-BHC level. One issue with the Summary of Deposits data is that the sample composition changes significantly in 1984, in particular because of the inclusion of thrifts to the dataset. To ensure that the composition of the sample remains similar throughout the sample period, we only include data from commercial banks that are present in the Call Reports.

We compute our measures of state-pair banking integration using these two different proxies for state-level bank lending. We present summary statistics of these measures of banking integration in Table I. We defer the definition of these measures to Section 3, as they will naturally emerge from our statistical model.

\subsubsection{Fundamental Proximity Measures}

For each state pair, each year, we first measure "fundamental comovement." We use the 5-year forward rolling correlation of personal income growth. The source is the quarterly data on personal income from the Bureau of Economic Analysis (BEA). Personal income is the income received by all persons from all sources: it is the sum of net earnings by place of residence, property income, and personal current transfer receipts. As we did for home prices, we also calculate two alternative measures of fundamental comovement: the covariance and average "beta" of personal income growth over the next 20 quarters. In a robustness check, we also use the correlation of changes in state-level unemployment rate as an additional control for "fundamental comovement". State-level unemployment statistics 
are obtained from the Bureau of Labor Statistics website. ${ }^{6}$

For each state pair and year, we also construct a measure of "economic proximity." Following ?, we calculate the distance in industry composition between the two states. The source is data from the BEA on state employment by industry. For each state in the pair, we first calculate the vector of employment shares in 20 industries and then compute the Euclidian distance between these two vectors. This number is large when the two states have very different industrial specializations. Summary statistics for these variables are reported in Table I. The average income correlation is high at .47, and it is negative for less than $5 \%$ of the observations. ${ }^{7}$

\subsection{Rising Correlations}

As shown in the introduction, Figure 1 plots the year-by-year distribution of correlations across state pairs from 1976 to 1996. Note that due to the way we compute correlation (5-year forward rolling window), this figure uses house price data up to 2000. Both the average and the median correlation increase from an average of 5\% in the 1976-1980 period to an average of about $40 \%$ in the $1992-1996$ period. In the same figure, we also report the evolution of the $25^{\text {th }}$ and $75^{\text {th }}$ percentiles of the distribution and confirm that the entire distribution shifts upward over the period. Strikingly, the $25^{\text {th }}$ percentile of the distribution of house price correlation is negative until the late 1980s. To gauge the statistical significance of this trend, we regress the average correlation across state pairs and regress it on a trend, adjusting for the five-year correlation in error terms with the Newey-West procedure. The fitted trend is equal to 0.015 with a t-stat of 5.3 .

This fact resists numerous robustness checks that we do not report for brevity. In particular, the trend remains large and statistically significant using three-year instead of five-year

\footnotetext{
${ }^{6}$ We do not include this control in all our specification as unemployment rates are available only from 1976 onward, which allows us to compute our correlation measure only from 1977 onward, which decreases our sample period by a year. We have, however, checked that all our results are similar if we include the correlation of changes in unemployment rates as a control variable.

${ }^{7}$ Our regressions include state-pair fixed effects. The geographic distance between states is absorbed by these fixed effects and is thus not included as a control.
} 
rolling correlations: +1.9 point per year, with a Newey-West adjusted t-stat of 5.4. Second, this trend is also present when we use MSA-level price indices from OFHEO. At the MSA level, average house price correlation across city pairs grows from .02 in 1980 to .18 in 1994 . Like the trend using state-level prices, the increase is strongly significant statistically and economically, and continues into the 2000s.

The fact on house price correlation presented so far uses data only up to 2000. However, the trend in house price correlation is far from reversed post-2000. To the contrary, after 2000, house price growth correlation increases even more quickly than it does up to 1996 : in 2006, the average five year forward correlation of house price growth across US states is above $75 \%$. ? document a similar rise in house price correlation over the 2000s using city-level data. Obviously, understanding the drivers of this rise in the correlation of house prices over the 2000s is important. We only stop in 2000 here because the primary purpose of the paper is to examine the effect of banking integration on house price comovement. As we explained in the introduction, establishing this causal link requires the use of exogenous shocks to banking integration. The interstate banking deregulation episode, which took place in the 1980s and 1990s, is the best available quasi-natural experiment. This explains our focus on historical data, but we believe that our mechanism is more general.

While different forces may partly explain the recent increase in comovement (?), we can also speculate that financial integration may have been a contributing factor. Banking deregulation ended in 1994 with the Riegle-Neal Act, but the movement toward banking integration did continue throughout the early 2000s. This integration took place mostly through the expansion of the largest banks. However, it one can hardly argue that this expansion was exogenous to the dynamics of local house prices, which makes an empirical analysis of recent data challenging. We thus favor the use of historical evidence, which allows us to establish cleanly the role that banking integration has on house price correlation. 


\section{A Framework to Measure Bank Integration}

This section develops a simple statistical framework to establish a testable relationship between house price comovement and a relevant measure of bank integration. Our framework allows for both aggregate and idiosyncratic shocks to the lending policy of banks (see ?).

\subsection{Basic Statistical Framework and Intuitions}

Our first assumption is that bank lending growth can be described as the sum of a bankspecific shock and an aggregate shock. Banks may operate in several states. $L_{i, t}^{k}$ is the lending of bank $k$ in state $i$ :

$$
\frac{\Delta L_{i, t}^{k}}{L_{i, t-1}^{k}}=a_{t}+\eta_{k, t},
$$

where $\eta_{k, t}$ is the idiosyncratic shock to the lending policy of bank $k$. The variance-covariance matrix of idiosyncratic shocks is given by $\Sigma_{\eta}=\sigma_{\eta}^{2} I d$, where $I d$ is the identity matrix. Bank-specific shocks can be interpreted as credit-supply shocks: for instance, idiosyncratic bank-funding shocks or bank-level decisions over lending growth. $a_{t}$ is the aggregate shock to bank lending. It can be interpreted as a shock to the supply of wholesale funding or as a shock to the aggregate demand for securitized loans. $\sigma_{a}^{2}$ is the variance of $a_{t}$. Finally, note that the model can easily include state-specific shocks $\zeta_{i, t}$, such as local credit demand shocks. Including these shocks does not materially affect our mathematical derivations. We opted for the simpler specification (1) to clarify the exposition.

The mechanism described in equation (1) rests on the presence of active, within bank, internal capital markets, that generate commonality in lending across divisions of the same bank. Such an effect has been documented in the banking literature (see, e.g., ?, ?, ?, ?), which shows that commercial banks or branches affiliated with a given entity respond to shocks affecting this entity. In Section 3.3, we offer a direct test of the role of internal capital markets on cross-state lending. 
Our second assumption is that lending shocks affect house prices (?; ?; ?). We posit that house price growth in state $i$ can be described by:

$$
\frac{\Delta P_{i, t}}{P_{i, t-1}}=\mu \frac{\Delta L_{i, t}}{L_{i, t-1}}+\epsilon_{i t},
$$

where we assume price shocks $\epsilon_{i, t}$ are independent of $\eta_{k, t}$ and $a_{t}$. The $\epsilon_{i, t}$ shocks can be thought of as "fundamental" shocks to house price growth, that is shocks that are unrelated to credit supply. The variance-covariance matrix of $\epsilon_{i, t}$ is given by $\Sigma_{\epsilon}=\sigma_{\epsilon}^{2}(\rho . J+(1-\rho) I d)$, where $J$ is the squared matrix of ones. $L_{i, t}$ is aggregate lending by all banks active in state $i: L_{i, t}=\sum_{k} L_{i, t}^{k} . \mu$ is the elasticity of house prices to bank lending.

We then combine equations (1) and (2) to compute the variance-covariance matrix of house prices across states:

$$
\begin{gathered}
\operatorname{Var}\left(\frac{\Delta P_{i, t}}{P_{i, t-1}}\right)=\sigma_{\epsilon}^{2}+\mu^{2} \sigma_{a}^{2}+\mu^{2} \sigma_{\eta}^{2} \underbrace{\left(\sum_{1}^{K}\left(\frac{L_{i, t-1}^{k}}{L_{i, t-1}}\right)^{2}\right)}_{H_{i i}} \\
\operatorname{Cov}\left(\frac{\Delta P_{i, t}}{P_{i, t-1}}, \frac{\Delta P_{j, t}}{P_{j, t-1}}\right)=\sigma_{\epsilon}^{2} \rho+\mu^{2} \sigma_{a}^{2}+\mu^{2} \sigma_{\eta}^{2} \underbrace{\left(\sum_{1}^{K} \frac{L_{i, t-1}^{k}}{L_{i, t-1}} \frac{L_{j, t-1}^{k}}{L_{j, t-1}}\right)}_{H_{i j}} .
\end{gathered}
$$

These two equations connect price volatility and covariance on the one hand, with bank market structure on the other hand. Equation (3) shows that house-price volatility depends on bank concentration through idiosyncratic shocks only. In the absence of idiosyncratic shocks, the structure of the banking market has no effect on house-price volatility. Because in our model, banks all have the same exposure to the aggregate shock $a_{t}$, the aggregate exposure to $a_{t}$ does not depend on market composition. When banks face idiosyncratic shocks, however, market structure matters. When banks are atomistic, the Herfindahl index $H_{i i}$ is small: idiosyncratic shocks cancel each other out and do not contribute to aggregate uncertainty. When lending activity is concentrated (the Herfindahl index $H_{i i}$ is closer to 
1), some banks are so large in their markets that their lending shocks are not cancelled out by other banks' shocks. These large banks then contribute significantly to aggregate fluctuations in lending.

The same intuition on the role of idiosyncratic shocks helps to interpret the covariance equation (4). The first term captures the fundamental comovement of house prices across states: $\rho_{\epsilon} \sigma_{\epsilon}^{2}$. The second term is the effect of the aggregate lending shock. Because banks operating in states $i$ and $j$ are subject to the same aggregate shock $a_{t}$, prices in these states tend to comove. Whether banks overlap the two states or are geographically segmented, the comovement induced by the common exposure to $a_{t}$ is the same: this second term is independent of banking integration. The third term represents the effect of idiosyncratic shocks on banks that overlap the two states. $H_{i j}$, the "co-Herfindahl" of states $i$ and $j$, is large when the same banks are large lenders in both states, and when the overlap is concentrated among a few banks. As in the variance equation, absent idiosyncratic shocks, banking integration would have no effect on house price comovement. Additionally, idiosyncratic shocks only matter when the market is concentrated enough. Hence, for banking integration to affect house price comovement, a few large overlapping banks need to be subject to substantial idiosyncratic shocks.

We now calculate house price correlation in the model. We make the linear approximation that $H_{i i}$ is small and obtain

$$
\begin{aligned}
\operatorname{corr}\left(\frac{\Delta P_{i, t}}{P_{i, t}}, \frac{\Delta P_{j, t}}{P_{j, t}}\right)=\left(\frac{\rho+\frac{\mu^{2}}{\sigma_{\epsilon}^{2}} \sigma_{a}^{2}}{1+\frac{\mu^{2}}{\sigma_{\epsilon}^{2}} \sigma_{a}^{2}}\right) & +\left(\frac{\frac{\mu^{2}}{\sigma_{\epsilon}^{2}} \sigma_{\eta}^{2}}{1+\frac{\mu^{2}}{\sigma_{\epsilon}^{2}} \sigma_{a}^{2}}\right) H_{i j} \\
& -\left(\frac{\left(\rho+\frac{\mu^{2}}{\sigma_{\epsilon}^{2}} \sigma_{a}^{2}\right) \frac{\mu^{2}}{\sigma_{\epsilon}^{2}} \sigma_{\eta}^{2}}{\left(1+\frac{\mu^{2}}{\sigma_{\epsilon}^{2}} \sigma_{a}^{2}\right)^{2}}\right) \frac{H_{i i}+H_{j j}}{2} .
\end{aligned}
$$

Equation (5) contains all the effects just discussed in the variance-covariance equations. The first term captures the effect of the aggregate lending shock as well as the correlation 
of fundamental determinants of house prices. For a given house price fundamental volatility $\sigma_{\epsilon}$, this first term increases with $\sigma_{a}$. This result formalizes the intuition that a more volatile "common factor" to bank lending would lead to larger house price correlation. The second term in equation (5) is the focus of our cross-sectional analysis: it captures the effect of idiosyncratic shocks on house price correlation (it disappears if $\sigma_{\eta}=0$ ). Idiosyncratic shocks generate more correlation when more banks overlap the two states, all the more so when these banks are large (and thus $H_{i, j}$ is large). The third term captures the variance effect: if states $i$ and $j$ both have concentrated banking markets, they will be sensitive to the idiosyncratic shocks of their large banks and will therefore be volatile, which, for a given level of covariance, lowers the correlation. In our empirical analysis, to focus on the role of the co-Herfindahl $H_{i j}$, we will absorb these terms with state-year dummies.

\subsection{Bank-Integration Measures in the Data}

We now go back to the data to calculate our measure of bank integration, the co-Herfindahl index $H_{i j, t}$. For each state pair $(i, j)$ and each year $t$, we calculate $H_{i j, t}=\sum_{k} s_{i, t}^{k} s_{j, t}^{k}$, where $k$ is the index of BHCs that have some lending activity in both states $i$ and $j$ and $s_{i, t}^{k}$ is the market share of $k$ in state $i$. We use two different measures for $s_{i, t}^{k}$. Our first measure computes this market share as the fraction of real estate loans held by $k$ in state $i$, divided by all real estate loans held by BHCs active in state $i$. We call this measure the lending co-Herdinhal. Our second measure, the deposit co-Herfindhal, computes this market share as the deposit market share of bank $k$ in state $i$, using the FDIC Summary of Deposits data.

We report descriptive statistics on these co-Herfindahls in Table I. The average lending coHerfindahl is small (0.003), and is equal to zero up to the $75^{\text {th }}$ percentile. This finding comes from the fact that because regulation was so effective at preventing the integration of banks across state lines, the lending co-Herfindahl is almost always zero before the deregulation of interstate banking. At the same time, because our sample starts in $1976,36 \%$ of the observations correspond to state pairs before deregulation, even though, in 1996, $100 \%$ of 
the state pairs allow interstate banking (?). Conditional on deregulation, the average coHerfindahl is 0.006 , compared to 0.001 prior to deregulation. This observation serves as the basis for our IV strategy: we explore the link between deregulation and bank integration more in depth in Section 4.1. The summary statistics for the deposit co-Herfindhals are very similar, which is not surprising since the correlation between deposit co-Herfindhals and lending co-Herfindhals is .76.

We show in Table II that bank integration rises sharply during the period. Column 1 of Table II shows that the average lending $H_{i j, t}$ is multiplied by more than three during our sample period. The increase really starts after 1985, which corresponds to the timing of interstate banking laws that we use as shocks to financial integration (see Section 4). We then decompose the co-Herfindahl into the contribution of the 20 largest BHCs by total assets nationwide (variable $\operatorname{rcfd} 2170$ in the call reports), and the contribution of all other BHCs. ${ }^{8}$ Columns 2 and 3 of Table II report the averages of the two components by subperiod. The numbers are consistent with the idea that bank integration increased in two steps. At first, in the 1980s, small banks merged and began to overlap in a few states but remained small and regional. Indeed, during this period, our integration measure rises when we take all banks, while the top-20 bank contribution remains flat. In the 1990s, a few nationwide players emerged: essentially all of the increase in bank integration is accounted for by the largest BHCs in the country. Column 4 to 6 replicates the analysis of columns 1 to 3 using the deposit co-Herfindhal instead of the lending co-Herfindhal as our mesure of banking integration. The findings are essentially similar.

An alternative explanation for the rise in house price comovement is that banks have comoved more over the period. In terms of equation (5), this effect would arise via an increase in aggregate volatility $\sigma_{a}$, which would happen, for instance, because banks relied more and

${ }^{8}$ More specifically, we write

$$
H_{i j, t}=\sum_{k \in \operatorname{Top} 20} s_{i, t}^{k} s_{j, t}^{k}+\sum_{k \notin \operatorname{Top} 20} s_{i, t}^{k} s_{j, t}^{k},
$$

where the first term is the contribution of the top 20 BHCs and the second term is the residual. 
more on the wholesale market to fund their mortgage issuance. As a result, common shocks to the demand for securitized loans, or common supply shocks to the wholesale funding market, may have made bank lending more synchronized at the nationwide level. We discuss this effect in Appendix B, and show that in the data, the opposite happens: we calculate $\sigma_{a}$ as the rolling volatility of average lending growth and find that it actually decreases over the period. In other words, the aggregate component in bank lending volatility has become smaller over our sample period: common shocks to bank lending policies cannot explain the observed rise in house price comovement.

\subsection{Internal Capital Markets and Lending Comovement}

In this section, we present bank-level evidence that internal capital markets induce positive lending correlation across states. Our strategy consists in showing that lending activity of BHCs active in several states tends to strongly comove across these states.

The first step consists in measuring lending activity of a BHC in each state. To do this, we assume, like in the rest of the paper, that all commercial banks belonging to $b$ and located in state $s$ only lend in state $s$. As previously discussed, this assumption is a good approximation until the enactment of Riegel-Neal. Based on this, we measure lending of each BHC $b$ in each state $s$ as the sum of all real-estate loans (call report item RCFD1410), made by all commercial banks belonging to $b$ and located in $s$.

We then run the following regression, for $\mathrm{BHC} b$, in state $s$ and date $t$ :

$$
\Delta \log L_{b, s, t}=\alpha+\beta \Delta \log \hat{L}_{b, s, t}+\gamma \Delta \log L_{b, s, t}^{*}+\epsilon_{b, s, t}
$$

where $L_{b, s, t}$ is all lending by $b$ in state $s ; \hat{L}_{b, s, t}$ is total lending by BHC $b$ in all other states but $s$. The coefficient of interest is $\beta$, the sensitivity of lending in state $s$ by bank $b$ to the overall lending of banks belonging to the same BHC, but located in different states. To control for local lending shocks, we also include $L_{b, s, t}^{*}$, which is the sum of all lending activity made by 
all BHC but $b$, in state $s$. All specifications include date fixed effects effects, and error terms are clustered at the state level.

We report regression results in Table III. Columns (1)-(3) offer evidence that lending policy of BHCs significantly comoves across states. In the first column, we do not control for local credit growth. $\beta$ is estimated at 0.1 with a $t$ stat of almost 7 . The coefficient does not change when we control for state-level lending shocks (column (2)). It marginally decreases but remains strongly significant in column (3), when we replace local lending shocks by more flexible state-by-quarter fixed effects.

Columns (4)-(7) show that this within-BHC comovement has not become stronger over time. This alleviates the concern that our subsequent estimates are driven by an increase in the depth of internal capital markets over time. ${ }^{9}$ To show this stability, we cut the sample into two subperiods: 1976-1991 and 1992-1995. The first subperiod is longer, but has a similar number of observations, due to the structure of our empirical design. ${ }^{10}$ Comparing columns (4) and (5), we see very little difference between the $\beta$ 's over the period. Column (6) formalizes the statistical test. Column (7) confirms the finding using state-by-quarter FEs.

\subsection{Bank Size and Volatility}

In our derivations, we assume that bank-level idiosyncratic shocks do not decrease with bank size. We do so mostly to simplify exposition. In Appendix A, we extend our analytical and empirical analyses to the case in which larger banks are less volatile. We find that the sizevolatility relationship is not strong enough to significantly affect our conclusions. In this section, we only provide the intuitions, and defer the thorough analysis to Appendix A.

Among non-financial firms, a negative relationship exists between size and volatility (see, e.g., ?). It can be related to the well-documented failure of Gibrat's law, namely that larger

\footnotetext{
${ }^{9}$ Even though such a trend, a priori affecting all BHCs, should be captured by our difference-in-difference setting.

${ }^{10}$ Before deregulation, BHCs are not allowed to overlap states (as clearly shown in Figure 2). Since they are single-state operations, they are not included in the sample estimating equation (6).
} 
firms have slower growth. In the case of banks, this relationship may arise because internal capital markets in large banks help diversify away idiosyncratic funding shocks. In our data, we find that larger banks are in fact less volatile. However, the relationship between bank size and volatility is weak. The upper bound of our estimates (see Appendix A) suggests that multiplying bank size by 1,000 leads to a reduction in loan growth volatility of about 3.8 percentage points in the cross section. This effect is statistically significant, yet not very large.

Even if small, this relationship between bank size and volatility may affect our measurement of bank integration. For our measure of bank integration $H_{i j, t}$ to be large, we need cross-state lending to be concentrated into a few large banks. If, however, large banks are less volatile, this effect is attenuated. To understand it, take the limit case in which large banks are a large collection of smaller banks. Then, idiosyncratic shocks to these small banks are diversified away, so that large banks have no idiosyncratic risk. In this case, they do not contribute to house price comovement and therefore should not appear in the measure of bank integration. The argument is more general. When larger banks are less volatile, the Co-Herfindahl $H_{i j, t}$ is an upward-biased measure of effective banking integration. This bias is small if bank shocks are close to being homoskedastic. If this approximation is wrong, however, estimating equation (5) generates incorrect estimates.

To check the validity of this approximation, we amend the definition of $H_{i j, t}$ to correct for the fact that larger banks are less volatile. As shown in Appendix A, this amounts to putting a smaller weight, determined by the link between volatility and size, on the market share products of larger banks. We show in Appendix A that this amended version of bank integration is strongly correlated with our simplified measure $H_{i j}$ (the correlation coefficient is .78). We then re-run our main estimations (Table VII), using the amended integration measure, and find similar effects (Table A.II). Comforted by this robustness check and in order to simplify the exposition, we focus, in what follows, on the approximation that bank shocks are homoskedastic. 


\section{Empirical Tests}

This section describes our empirical strategy and then presents our main results.

\subsection{Empirical Strategy}

We take equation (5) to the data. Denoting $\rho_{i j, t}$ the correlation of house prices between state $i$ and state $j$ and $H_{i j, t}$ the co-Herfindahl across state $i$ and $j$, we start from the following "naive" estimating equation:

$$
\rho_{i j, t}=\alpha_{i j}+\delta_{t}+\mu_{i t}+\nu_{j t}+\beta H_{i j, t}+\gamma X_{i j, t}+\epsilon_{i j, t}
$$

where $\alpha_{i j}$ are state-pair fixed effects, $\delta_{t}$ are year fixed effects, $\mu_{i, t}$ and $\nu_{j, t}$ are state-by-year fixed effects for each state in the pair and $X_{i j, t}$ are time-varying control variables for the state pair $i j$. In particular, $\mu_{i, t}$ and $\nu_{j, t}$ entirely absorbs all variations that could come from changes in the state-level Herfindahl index (the $H_{i i}$ and $H_{j j}$ in equation (5).

$\beta$ in equation (10) is our main coefficient of interest. However, an OLS estimation of equation 10 may not yield an unbiased estimate of $\beta$. For instance, it may be that banking markets become more integrated when business cycles become more synchronous. Since housing cycles are correlated with business cycles, this would lead to a positive correlation between banking integration and house price correlation, which would be unrelated to banking integration. Of course, one solution to this issue is to control directly for this omitted variable, the correlation of income growth across state-pairs, which we do in most of our regressions. This solution is imperfect. Other unobservables might correlate with both banking integration and house price correlation, leading to a bias in the estimation of equation (10).

In order to account for the potential endogeneity of equation (10), we instrument $H_{i j, t}$ using interstate banking deregulations as shocks to financial integration. We rely on data compiled by ? and ?. Between 1978 and 1994, various states allowed banks from other states to enter their banking markets via M\&As. These deregulations typically, but not 
always, took place on the basis of reciprocity. $33.8 \%$ of the state-pair deregulations were "national non-reciprocal": one state would allow banks from all other states to enter its market; and $21.6 \%$ were "national reciprocal": one state would open its market only to states that open their markets too. The third most common deregulation method was through "bilateral reciprocal" agreements $(8.8 \%)$. We refer the reader to ? for more details on these deregulations. In 1995, the Riegle-Neal Act generalized interstate banking to all state pairs that had not deregulated before.

We believe these bilateral deregulations provide valid instruments for banking integration in equation (5). The identifying assumption is that these pairwise deregulations are not correlated with the unobserved heterogeneity in house price comovement. In particular, this assumption implies that states did not cherry-pick the states with which they deregulated interstate banking based on their expectation of future house price correlation. Because we control for the realized correlation of income growth in our regressions, we allow for the possibility that states were more likely to deregulate interstate banking with other states where fundamentals were about to become more integrated. In other words, the identifying assumption is that the pairwise deregulations are not correlated with the "non-fundamental" unobserved heterogeneity in house price comovement. We believe this assumption is credible. First, the fact that many deregulations were national in nature (reciprocal or non-reciprocal) suggests states did not pick the states with which they would deregulate. Bilateral reciprocal agreement could create such a concern, but they are a minority. Second, the political economy of these reforms does not seem to have involved the mortgage market, but rather the relative lobbying effort of small banks, which favored the status-quo of segmented banking markets, and small firms, which wanted increased banking competition (?). Third, the data suggests that deregulations do precede the rise in house price correlation: while house price comovement is mostly flat before the deregulation of interstate banking in a state pair, it rises sharply right after the deregulation becomes effective. Finally, we include in our specifications a large number of controls and fixed effects. We add the full set of state-pair 
fixed effects, state-year fixed effects for each state in the state pair, and also control for the proximity in industrial composition, as well as correlation of state-level income. As robustness checks, we also control for state-pair-specific trends, as well as another proxy for the correlation of fundamentals across states, namely the correlation of changes in state-level unemployment rates.

The exclusion restriction in our empirical strategy is that interstate banking deregulation affected house price correlation only through banking integration. One alternative view on these interstate banking deregulations is that they led to an increase in business cycles synchronization (perhaps through banking integration), which in turn led to an increase in house price co-movement. In Appendix C, we show that the data do not support this alternative view: the deregulation of interstate banking between state $i$ and state $j$ does not lead to an increase in the correlation of personal income growth between state $i$ and state $j$ in the years following the deregulation. Appendix $\mathrm{C}$ details how we reach this conclusion. While this does not validate our exclusion restriction, it at least shows that banking deregulation did not lead to an increase in house price correlation through an increase in income comovement.

\subsection{Interstate Banking Deregulation Increases Banking Integra- tion}

This section tests for the relevance of our instrument. First, the raw data show that interstate banking deregulations have a strong impact on the level of bank integration in a state-pair. In Figure 2, we make as little treatment of the data as possible. We simply plot the average lending co-Herfindhal $H_{i j, t}$ as a function of the number of years relative to the year of deregulation. To control for the aggregate evolution in banking integration, we adjust every year the measure of $H_{i j, t}$ by subtracting the mean co-Herfindahl for those state pairs that will not deregulate in the next five years. These states serve as a benchmark for what happens to integration $H_{i j, t}$ in the absence of interstate banking deregulation. As can be seen in Figure 2, the average adjusted co-Herfindahl is flat before the reform and close to zero, and 
then starts to pick up at the time of the bilateral banking deregulation. The deregulations therefore impulse a clean break in the pattern of banking integration, which comforts us in their validity as instruments for banking integration in equation (10).

Because our second-stage equation explains a rolling measure of house price correlation with a state pair's co-Herfindahl, we also use a rolling average of the co-Herfindahl index as our dependent variable in the first-stage regression. For each state-pair-year in our sample, we define the five-year rolling average of $H_{i j, t}: H_{i j, t}^{m}=\frac{1}{5} \sum_{k=0}^{k=4} H_{i j, t+k}$. Because it is rolling, this measure only responds progressively to the regulatory shocks, as does our measure of house price comovement, which is defined over a similar five-year rolling window. We only report regression results using this measure of integration. Our results, however, do not depend on this assumption and remain strongly significant when we use the current co-Herfindahl.

For a state pair $(i, j)$ in year $t$, we estimate the following first-stage equation:

$$
H_{i j, t}^{m}=\alpha_{i j}+\delta_{t}+\mu_{i t}+\nu_{j t}+\phi_{i j} \times t+\beta \times \text { After Deregulation }_{i j, t}^{m}+\gamma \times X_{i j, t}+\epsilon_{i j, t},
$$

$\alpha_{i j}$ is a state-pair fixed effect, designed to control for composition effects that arise from the timing of deregulation by heterogeneous state pairs. $\delta_{t}$ are year fixed effects that capture nationwide trends in bank integration potentially unrelated to the reforms. $X_{i j, t}$ capture time-varying measures of state similarity that may correlate with the reform. We include the five-year forward correlation of state-level personal income growths, proximity in industry structure, and the log of states $i$ and $j$ 's total labor income. $\mu_{i t}$ and $\nu_{j t}$ are state $i$-by-year and state $j$-by-year fixed effects, which will absorb any source of variations coming from stateyear shocks. $\phi_{i j} \times t$ are state-pair specific trends and allow for the possibility that state-pairs experience diverging trends in house price correlation. Standard errors are two-way clustered at the state $i$ and state $j$ level.

After Deregulation ${ }_{i j, t}^{m}$ is the five-year forward rolling average of a dummy equal to 1 when both states in the pair have opened their banking markets to the other state in the pair. 
The reason for taking the 5-year rolling average of a post-deregulation dummy is to account for the fact that our dependent variable is itself defined as a 5-year rolling window average. $11 \beta$ thus captures the extent to which, on average, the deregulation of interstate banking affects a state-pair co-Herfindahl $H_{i j}^{m}$.

We report estimates of various specifications based on equation (8) in Table IV. Banking integration is measured with the lending co-Herfindhal (Panel A) and the deposit coHerfindhal (Panel B). Below, we describe the results obtained with the lending co-Herfindhal. The results using the deposit co-Herfindhal are essentially similar.

The first column only has time fixed effects and no other controls. We are using 25,725 observations, which correspond to the 1976-1996 period, since our rolling co-Herfindahl $H_{i j, t}^{m}$ requires five years of data from the call reports. Consistent with the graphical evidence presented in Figure 2, After Deregulation ${ }_{i j, t}^{m}$ is positive and statistically significant at the $1 \%$ confidence level. The estimated effect is 0.0095 (t-stat of 4.5): banking integration in deregulated state pairs is 0.0095 higher than in state pairs that have not yet deregulated. This number is large: it corresponds to approximately one sample standard deviation of the co-Herfindahl measure. The deregulation of interstate banking thus has a large and significant effect on banking integration. Column (2) further controls for the sizes of state $i$ and state $j$ (measured through the logarithm of state-level income), the similarity in industry composition $\Sigma$, as well as the five-year forward correlation of personal income between the two states. The estimate is unchanged. Column (3) adds state-pair fixed effects. The point estimate drops to .0039 , but remains significant at the $1 \%$ confidence level. This effect still remains economically significant, since it explains about a third of the sample standard deviation of $H_{i j, t}^{m}$. Column (4) includes, in addition to the state-pair fixed effects, state-year fixed effects for both states in the state pair $\left(\mu_{i t}\right.$ and $\left.\nu_{j t}\right)$. This is an important control

\footnotetext{
${ }^{11}$ The estimation of equation (8) yields similar estimates if we use instead the current co-Herfindahl $H_{i j, t}$. Figure 2 shows that in fact, there is a clear instantaneous response of $H_{i j, t}$ to the deregulation of interstate banking. Our favorite specification remains equation (8) however, since we are looking to be consistent with the second-stage regression that uses rolling correlations as dependent variables.
} 
as the deregulation of interstate banking could be associated with changes in state-level output volatility, which in turn could affect banking integration. State-year fixed effects ensure that the estimated $\beta$ is not driven by such an effect. As it turns out, the inclusion of these additional fixed effects lead to an increase of the estimated $\beta$ at .0057 (t-stat of 4.5). Overall, the estimated effect of interstate banking deregulation on banking integration is positive and significant across these first specifications. The effect varies from .004 to .01, such that interstate banking deregulation can explain an increase in banking integration of about .5 to .9 sample standard deviation of $H_{i j}^{m}$.

The next three columns of Table IV checks the robustness of these results to the definition used for our main explanatory variable, After Deregulation ${ }_{i j, t}^{m}$. These are important specification checks that help validate the robustness of our first-stage results. First, we start by restricting the analysis to years where the 5 -year rolling average $H_{i j}^{m}$ is computed using observations that are either entirely pre-deregulation or entirely post-deregulation, i.e. years $t$ such that $t \notin\left[T^{i j}-4, T^{i j}\right]$, where $T^{i j}$ is the year of deregulation of interstate banking for state-pair $(i j)$. The analysis is then akin to a standard difference-in-difference and leads to a point estimate within the range obtained in Column (1) to (4), i.e. .0061 (t-stat of 4.7). Second, we break down the variable After Deregulation ${ }_{i j, t}^{m}$ into two components: (1) $\frac{t-\left(T^{i j}-4\right)}{5} \cdot \mathbb{1}_{T^{i j} \geq t>T^{i j}-4}$, where $T^{i j}$ is the year of deregulation of the state-pair $(i j)$; this variable is simply the 5-year rolling average of the post-deregulation dummy for all the years preceding the deregulation $(2) \mathbb{1}_{t>T^{i j}}$, which is simply the 5 -year rolling average of the post-deregulation dummy for all the years following the deregulation. This decomposition allows the initial effect of the deregulation to differ from its long term effect. It still imposes a linear structure in the treatment effect, in the sense that on the year of deregulation $\left(t=T^{i j}\right)$, the effect of interstate banking deregulation is assumed to be 4 time larger than 3 years before deregulation $\left(t=T^{i j}-3\right)$, which matches the fact that for $t=T^{i j}, H_{i j, t}^{m}$ is defined using 4 years of observations post-deregulation while for $t=T^{i j}-3, H_{i j, t}^{m}$ uses only one year of observations post-deregulation. This specification also leads to a significant 
and positive effect of the deregulation of interstate banking on co-Herfindahl. Column (6) shows that following banking deregulation, the rolling co-Herfindahl $H_{i j}^{m}$ increases by about .0064 (t-stat of 4.7), again within the range of point estimates obtained in Column (1) to (4). Column (6) also shows that in the years leading up to the deregulation, the rolling co-Herfindahl starts increasing by about .0015/5 =.0003 per year. Third, we offer in Column (7) a similar breakdown, without imposing the linear structure, i.e. we break down the variable After Deregulation ${ }_{i j, t}^{m}$ into two dummies (1) $\mathbb{1}_{t \leq T^{i j}}$ and (2) $\mathbb{1}_{t>T^{i j}}$. Again, we find that following the deregulation of interstate banking, the 5-year rolling co-Herfindahl increases by .0057 (t-stat of 4.4). Thus across these three alternative specifications, we find an effect of interstate banking deregulation on banking integration that is similar, both in terms of magnitude and significance, to the specifications of Column (1) to (4).

Finally, in Column (8), we perform an important robustness check. The location of BHC assets becomes ill-measured in the call reports after the Riegle-Neal Act is implemented, i.e. after 1994. We thus simply replicate the specification of Column (4), but restrict the sample period to 1976-1990, so that no post-Riegle-Neal Act observations are used in the computation of $H_{i j}^{m}$. Because of this reduced sample period, the sample size drops to 18,345 observations. Despite this reduction in sample size, the estimate remains strongly significant and qualitatively similar with a point estimate for $\beta$ of .0072 (t-stat of 5.2).

\subsection{Bilateral Reforms Increase House Price Comovement}

Before turning to IV regressions, we verify that interstate banking deregulations have directly caused an increase in house price correlation. Since we know that deregulations increased bank integration, and if we conjecture that integration affects comovement, as in equation (5), then deregulations should directly affect comovement. In this section, we test for the presence of this reduced-form relationship. The advantage of this reduced-form approach is that it does not rest on the validity of the call reports data to measure the location of bank assets. 
We first look at the raw data in Figure 3. We follow the same methodology as in Figure 2. We plot the average correlation of house price growth $\rho_{i j, t}$ as a function of the number of years relative to the year of deregulation. To control for the aggregate evolution in house price correlation, we adjust every year our price correlation measure by subtracting the average correlation of house price growth for those state pairs that will not deregulate in the next five years. These states serve as a benchmark for what happens to correlation $\rho_{i j, t}$ in the absence of interstate banking deregulation. Figure 3 shows that following the deregulation of interstate banking, house price growth correlation increases by an average of 20 percentage points. This sharp increase occurs a couple of years after the deregulation. Because we measure correlation using a forward rolling window, this means that banking reforms started to affect the correlation structure of house prices two years after they were enacted. Importantly, the mean-adjusted correlation is flat in the pre-reform period, which we again interpret as consistent with the validity of these reforms as instruments to banking integration in equation (10).

We estimate the following reduced-form equation:

$$
\rho_{i j, t}=\alpha_{i j}+\delta_{t}+\mu_{i t}+\nu_{j t}+\phi_{i j} \times t+\beta \times \text { After Deregulation }_{i j, t}^{m}+\gamma \times X_{i j, t}+\epsilon_{i j, t},
$$

where $\rho_{i j t}$ is the five-year rolling forward correlation of house price growth and the independent variables have been defined in Section 4.2. Again, standard errors are two-way clustered at the state $i$ and state $j$ level.

Table $\mathrm{V}$ follows the presentation of Table IV and presents the estimation results from various specifications based on equation (9). Panel A presents the estimation results using the raw house price growth data from OFHEO; Panel B presents the estimation results using seasonally-adjusted house price growth data. Below, we describe estimation results using the raw house price data. The results using the seasonally-adjusted data are essentially similar. Column (1) only has year fixed effects: in state pairs in which interstate banking 
is deregulated, house price growth correlation increases by 7.4 percentage points relative to state pairs that are not yet integrated (t-stat of 2.4). Columns (2) adds the time-varying state-pair-level controls (log of state-level personal income, proximity in industry structure, state-pair income correlation). As expected, income correlation has a large and significant predictive power on house price growth correlation, but does not affect our coefficient of interest, which becomes .065 (t-stat of 2.5). Column (3) adds state-pair fixed effects: after interstate banking is deregulated between states $i$ and $j$, the correlation of house price growth between states $i$ and $j$ increases by 5.7 percentage points relative to a state-pair that does not deregulate in the same time period. This large economic effect explains about $18 \%$ of the sample standard deviation in house price growth correlation and is significant at the 5 percent confidence level. In column (4), we add state-year fixed effects for both states in the pair $\left(\mu_{i t}\right.$ and $\nu_{j t}$ in equation 9). These additional fixed effects fully control for changes in state-level volatilities that could arise from variations in the state-level banking Herfindahl index. These additional fixed effects increase our point estimate of $\beta$ to .096 (t-stat of 3.6).

In column (5) to (7), we repeat our specification tests, namely: (1) we exclude the four years preceding the deregulation from the sample (Column (5)); (2) we break down our After Deregulation ${ }_{i j, t}^{m}$ variable into (i) a pre-deregulation trend for years $\left[T^{i j}-4, T\right]$ and (ii) a post-deregulation dummy (Column (6)) (3) we break down our After Deregulation ${ }_{i j, t}^{m}$ variable into (i) a pre-deregulation dummy for years $\left[T^{i j}-4, T\right]$ and (ii) a post-deregulation dummy (Column (7)). These three alternative specifications all show a significant effect of interstate banking deregulation on the long-run level of correlation across state-pairs whose banking markets become integrated. Finally, column (8) shows that this conclusion is robust to reducing the sample period to the 1976-1990 period, where the location of commercial banking assets is better measured. Over this restricted sample, we find that the deregulation of interstate banking between two states leads to an increase in the correlation of house price growth of about 11 percentage points (t-state of 3.9).

We represent our results graphically in Figure 4. In this figure, we run the specification 
of Table V, column (4), but we split the After Deregulation ${ }_{i j t}^{m}$ variable into 10 dummies: 8 dummies for each of the 8 years preceding deregulation, 1 dummy for the first year after deregulation and 1 dummy for all years after that. The event window we are using is asymmetric to account for the fact that correlation is measured using a five year forward window. Figure 4 reports each of these 10 points estimates, along with their $95 \%$ confidence interval. This figure delivers two insights. First, before the deregulation, house price correlation is flat. Second, a clean break occurs as the reform starts and correlation starts to grow. In Figure 4, the correlation reacts two years before the banking markets become integrated, which is reasonable given that correlations are computed using a five year forward rolling window.

To test the robustness of our analysis, we perform the following placebo analysis (see ?). First, for each state pair, we randomly draw deregulation dates with replacement from the empirical distribution of deregulation dates. We then re-run the regression of column (4), Table V using these randomly drawn deregulation dates. We perform this procedure 100 times and plot the distribution of the $100 \beta$ estimates in Figure 5. We find that the average estimate of all placebo regressions is .002, much smaller than our estimate (.096). Overall, we can only reject the null of 0 at the $10 \%$ (resp 5\%) confidence level for only $6 \%$ (resp. $3 \%$ ) of the simulations.

Table VI provides additional robustness checks on the reduced-form regression. Column (1) re-estimate the specification of Column (3) in Table V, but exclude state-pairs where the deregulation took place as a bilateral reciprocal deregulation. ${ }^{12}$ For these deregulations, the identifying assumption is harder to defend, as one may worry that states are cherry-picking which states they deregulate with. Over this restricted sample of state-pairs, the point estimate of $\beta$ is actually larger than that estimated over the whole sample (.18*** vs. .057**). All the other robustness checks are based on the specification of Table V, Column (4). In

\footnotetext{
${ }^{12}$ This robustness check does not use the specification in Column (4) of Table V, which has state-by-year fixed effects for each state in the pair, since the removal of bilateral reciprocal deregulation removes most source of identification for these fixed effects.
} 
column (2), we include state-pair specific trends and obtain a very similar estimate to that of

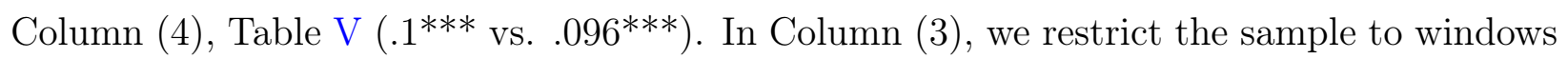
of five years around the year of interstate banking deregulation. These narrower sample periods limit the possibility that other state-pair-level events occurring far away from the deregulations bias our estimates. Over this restricted sample, our point estimate of $\beta$ is larger than in our baseline regression, equal to .16 (t-stat of 5.1). Column (4) adds an additional control variable ("After First Deregulation"), which is the five-year forward average of a dummy equal to 1 after the first unilateral deregulation of the state pair. For approximately half of the state pairs, interstate banking deregulation is not symmetric at first: one state allows banking from the other state without reciprocity. Column (4) shows that all of the rise in house price growth correlation following the deregulation of interstate banking takes place after both states in the pair have opened their banking market to banks from the other state. The "After First Deregulation" variable is insignificant and small, whereas the point estimate of the "After Deregulation" variable is unchanged at .1. Column (5) shows that our main result is robust to the horizon we use to compute the various correlations. In this specification, all rolling variables are computed using a three-year rolling window instead of a five-year rolling window. The estimate we obtain with a three-year horizon is similar to our baseline results (point estimate of .078, with a t-stat of 3.2). Column (6) shows that our main result is left unchanged if we do not control for the correlation of personal income growth: although the correlation of income growth is a priori an important control given that it is likely correlated with both the deregulation of interstate banking and with house price correlation, its inclusion in the regression does not change the inference we draw on $\beta$. Column (7) shows that our main reduced-form result is robust if we add the correlation in changes in unemployment rates between the two states in the pair as an additional control. ${ }^{13}$ Columns (8) and (9) use alternative measures of house price comovement. Column (8) shows the effect of the deregulation of interstate banking on house price comovement measured as

\footnotetext{
${ }^{13}$ Note that because state-level unemployment is available only from 1976 onward, this limits the analysis to 1977 onward, so that we lose one year of observation.
} 
the average beta of house price growth in the state pair. This measure has been used in part of the literature on financial contagion (?). ${ }^{14}$ The deregulation of interstate banking does lead to a large and significant increase of about 8.3 percentage points of this measure of house price comovement: this represents. This increase is economically large (20\% of the sample standard deviation of average beta). Finally, column (9) uses the covariance of house price growth as our dependent variable. Because the covariance is not a scaled measure, its empirical distribution is much noisier and contains a non-trivial amount of outliers. We deal with this issue by windsorizing the covariance of income growth and house price growth using the median plus/minus five times the interquartile range as thresholds for the distributions. ${ }^{15}$ We find again a large increase in house price growth covariance following the deregulation of interstate banking in a state-pair. The effect is of about 21 percentage points, which represents $15 \%$ of the sample standard deviation of house price growth covariance. This effect is significant at the $5 \%$ confidence level.

\subsection{Banking Integration and House Price Comovement: OLS and IV}

We now turn to our main estimating equation, equation 10, which we described in Section 4.1:

$$
\rho_{i j, t}=\alpha_{i j}+\delta_{t}+\mu_{i t}+\nu_{j t}+\beta H_{i j, t}^{m}+\gamma X_{i j, t}+\epsilon_{i j, t}
$$

Equation 10 is estimated in Table VII. Panel A uses the raw price correlation measure as a dependent variable, while Panel B uses the seasonally-adjusted house price correlation measure. Column (1) to (6) measures $H_{i j}$ using the lending co-Herfindhal; Column (7) to (12) measures $H_{i j}$ using the deposit co-Herfindhal. Column (1), (4), (7), (10) provide OLS estimation of Equation 10. Columns (2), (5), (8) and (11) provide IV estimation where a state pair's co-Herfindahl is instrumented using the specification in Column (6) of Table IV.

\footnotetext{
${ }^{14}$ Section 2.1 describes the construction of our average beta measure.

${ }^{15}$ This result is robust to, instead, windsorizing at the $1^{\text {th }}$ percentile or the $5^{\text {th }}$ percentile.
} 
Columns (3), (6), (9) and (12) use the specification of Column (5) of Table IV to instrument for $H_{i j}$. Column (1)-(3) and (7)-(9) of Table VII use the whole sample for estimation, i.e. the 1976-1996 period. As we already emphasized, one drawback of this longer sample period is that we use information on bank assets location from the call reports for post-Riegle Neal Act years. This information is not necessarily precise. As a robustness check, we therefore re-run the estimation of equation (10) over the 1976-1990 period. We report the results in columns (4)-(6) and (10)-(12). As in previous regressions using this restricted sample, the number of observations drops to 18,375. Below, we comment on the results in Panel A, using the non-seasonally adjusted correlation measure. Results in Panel B are quantitatively very similar.

In column (1), the OLS estimation provides a point estimate of 1.9 (t-stat of 2.2). A one standard-deviation increase in the co-Herfindahl leads to a $6.4 \%$ standard deviation increase in house price growth correlation. The IV estimations, reported in Column (2) and (3) provide much larger point estimates for the effect of $H_{i j, t}^{m}(8.9$ and 13, with t-stat of 2.7 and 2.4 respectively). This result suggests that the OLS estimate is biased downward, probably due to measurement error (our measure of banking integration imperfectly proxies for the actual banking integration of the state pair). Given the average IV estimate in Column (2) and (3), a one standard deviation increase in co-Herfindahl leads to an increase in house price growth correlation of about 12 percentage points, which represent a $37 \%$ standard deviation increase in house price correlation. The results from the shorter sample period yields a larger OLS estimates of 4.2 (as opposed to 1.9 over the entire sample period). The IV estimates, however, are of similar magnitude, at 14 and 11 in Columns (5) and (6) respectively. Our results are thus not driven by the inclusion of post-Riegle Neal Act observations to compute the correlation of house prices.

Taking these cross-sectional estimates to the time-series, we find the rise in banking integration has the power to explain approximately one fourth of the overall increase in house price comovement between 1976 and 1996. From Table II, we see the average co- 
Herfindahl $H_{i j t}^{m}$ increases from .0016 to .0045 over this period. Given a coefficient estimate of 10.95 (average of coefficient in Column (2) and (3) of Table VII), our estimation explains an increase in house price correlation of $0.0029 \times 10.95 \approx 3.2$ percentage points over this period, compared to an overall observed increase in correlation by about 14 ppt over the same period (see Figure 1). As shown in Table II, the emergence of the 20 largest banks in the country explains almost all of this evolution.

\section{Conclusion}

This paper has shown that the integration of the US banking market in the 1980s and the 1990s has led to synchronization of house prices across US states. We thus provide evidence that freeing capital flows - at least through the banking system - can lead to significant contagion across geographic regions. In doing so, we highlight the importance of idiosyncratic risk in shaping the relationship between bank integration and asset prices comovement. This paper thus contributes to the international finance literature on the link between contagion and capital market movements.

We do not claim that banking integration explains all of the rise in U.S. house price comovement. One obvious other candidate is the rise of securitization. The size of the funding pool available for originate-to-distribute lenders has dramatically increased over the past 30 years. Demand or price shocks on the securitization market directly affect the lending ability of all lenders that rely on it (regular banks, but also pure-play originators that are not in our data). And if this form of lending becomes more and more prevalent, this makes aggregate mortgage lending more and more sensitive to conditions on the securitization market. This has the power to induce comovement. Exploring this channel directly is an interesting lead for future research.

More broadly, the paper documents that interstate banking deregulations led to a large wave of capital market integration in the United States (see also ?; ?), with a few large banks 
slowly becoming the national key players. This finding suggests researchers can further use these deregulations as natural experiments to test macroeconomic models regarding the economic effects of capital markets integration. 
References 


\section{Tables and Figures}

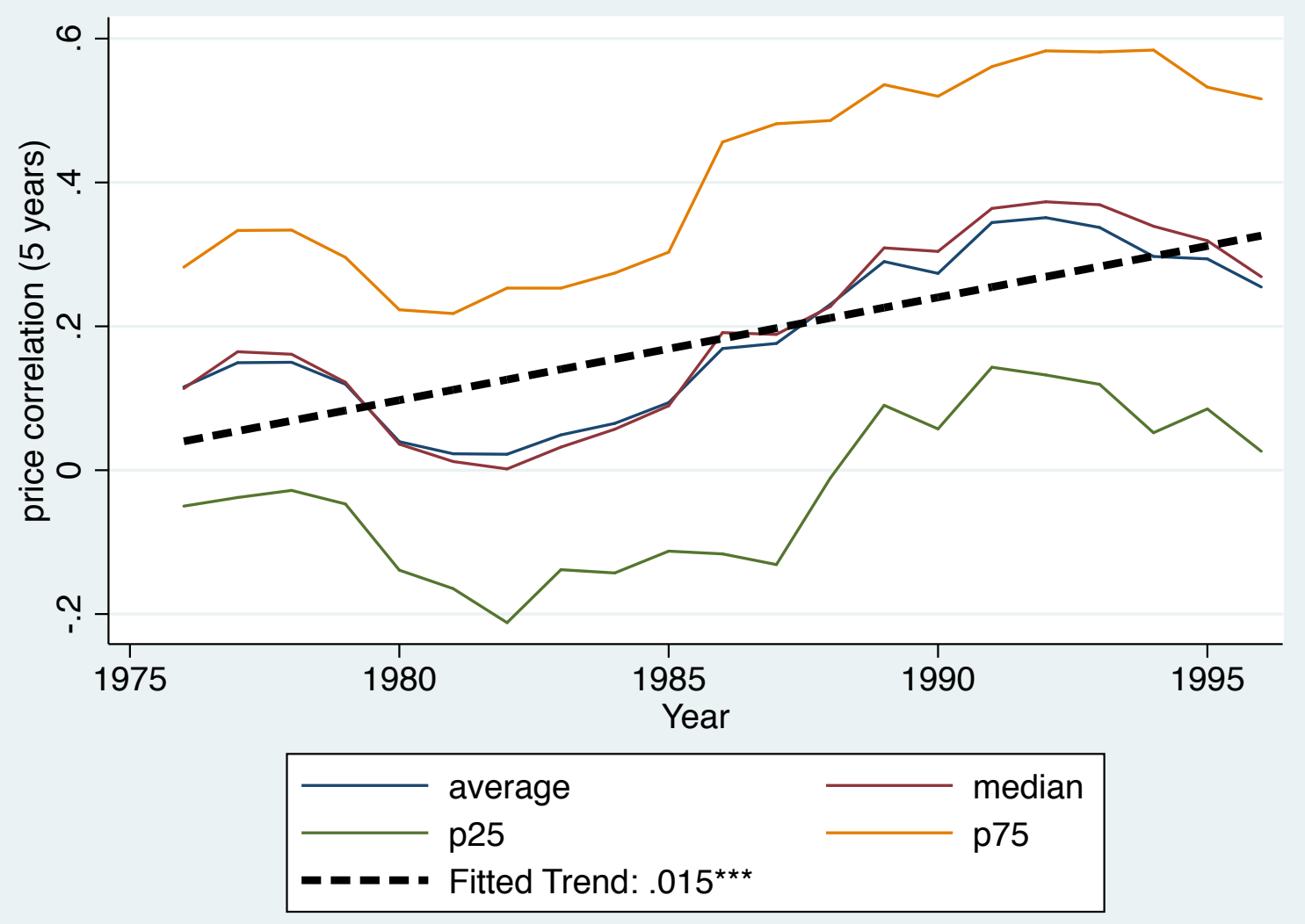

Figure 1: Pairwise Correlation of Real Estate Price Growth across US States: 19761996.

Source: OFHEO real estate price index. Note: This figure plots the mean, median, $25^{\text {th }}$, and $75^{\text {th }}$ percentiles of the distribution of pairwise correlations of real estate price growth across US states for the 1976-1996 period. Correlation is computed using a 5-year forward rolling window with quarterly data. 


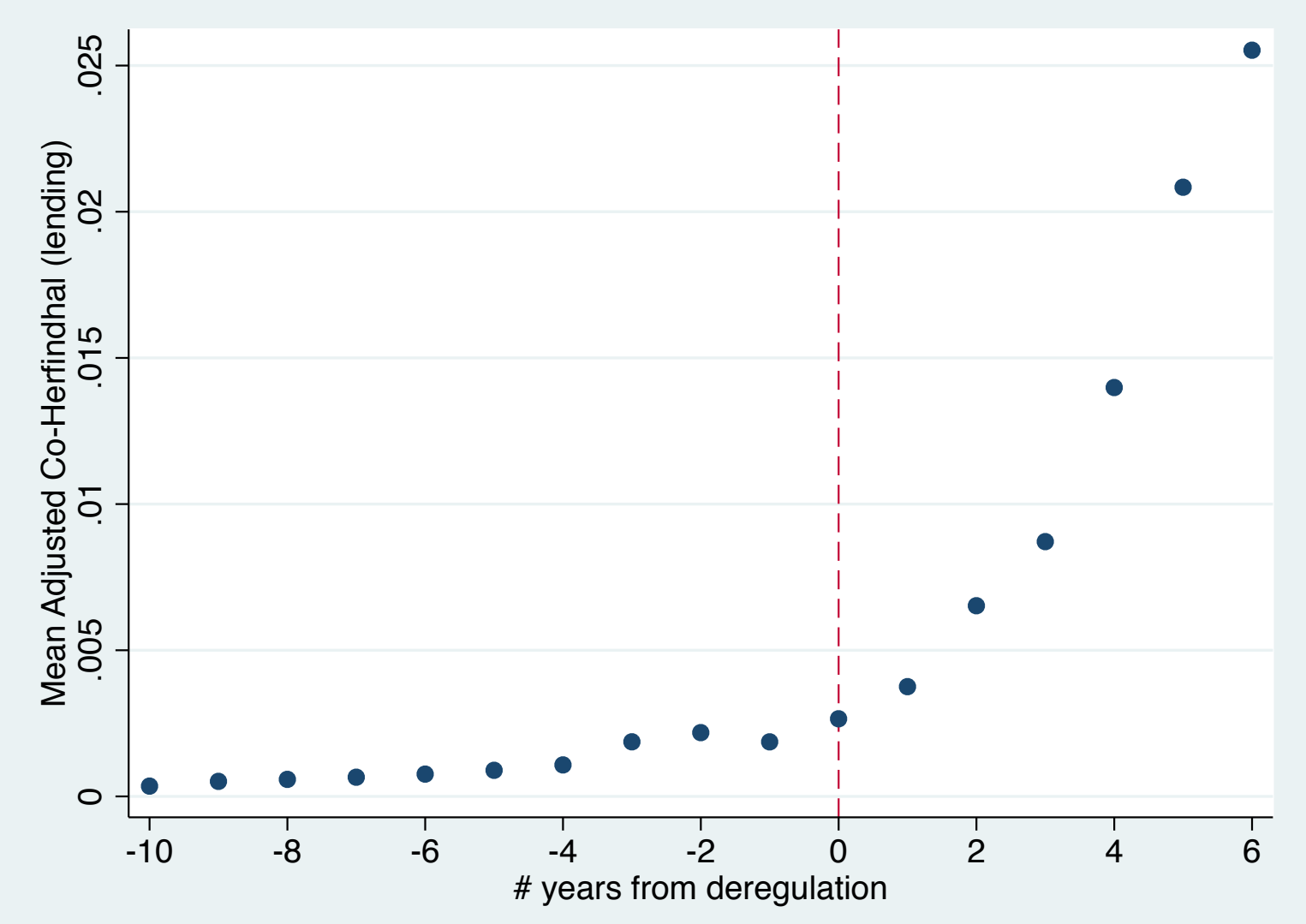

Figure 2: Banking Integration and Interstate Banking Deregulation.

Source: Call Reports. Note: This figure plots the average adjusted lending co-Herfindahl of banking assets across pairs of US states as a function of the time to deregulation of interstate banking in the state-pair. Lending Co-Herfindahls are adjusted by the median lending co-Herfindahl of states in the same year that will not deregulate in the next five year. The lending co-Herfindahl $H_{i j}$ is defined in Section 3. 


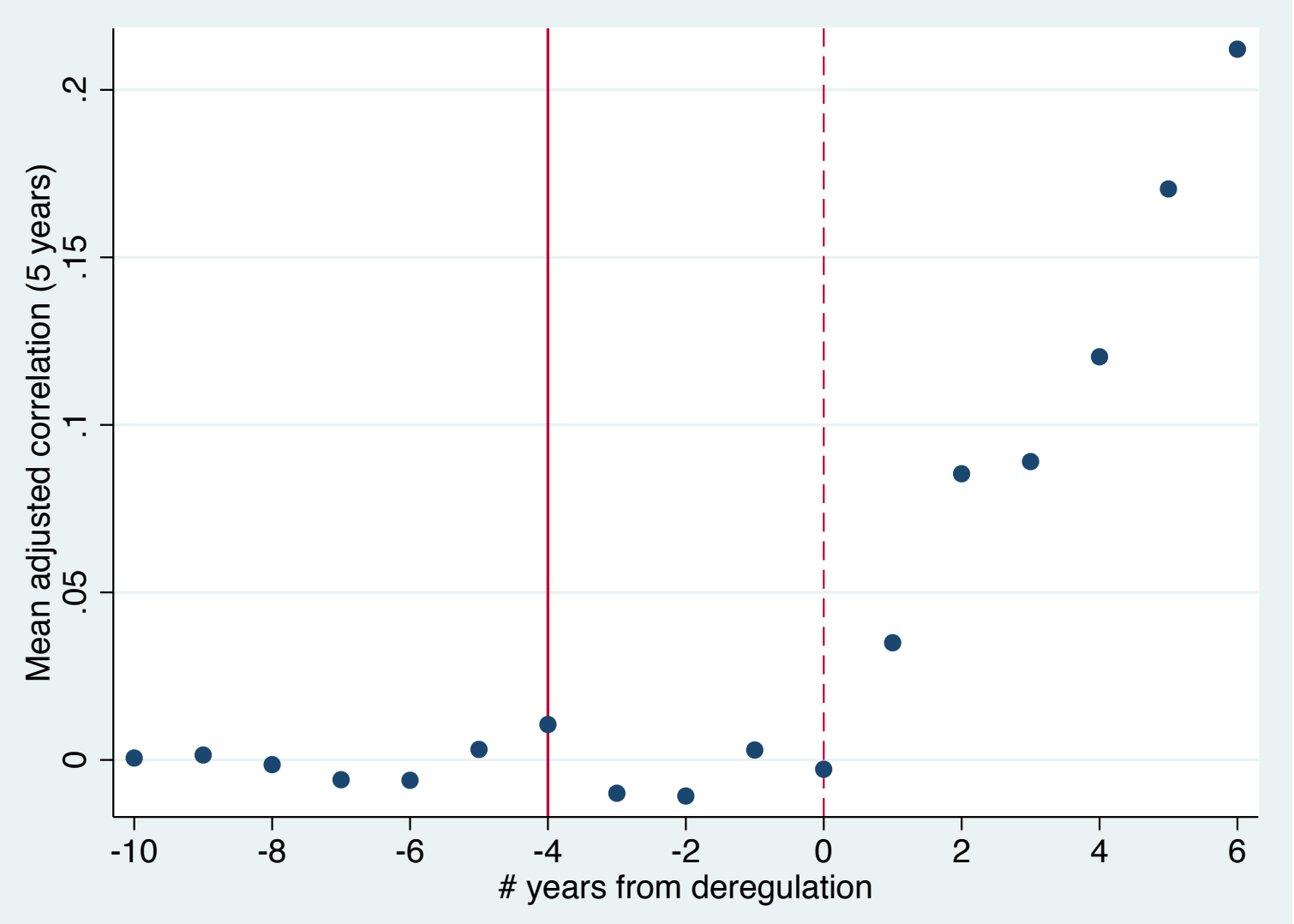

Figure 3: Real Estate Price Correlation and Interstate Banking Deregulation

Source: call reports. Note: This figure plots the average adjusted-house price growth correlation across pairs of US states as a function of the time to deregulation of interstate banking in the state-pair. House price growth correlations are adjusted by the mean correlation for states that will not deregulate in the next five year. 


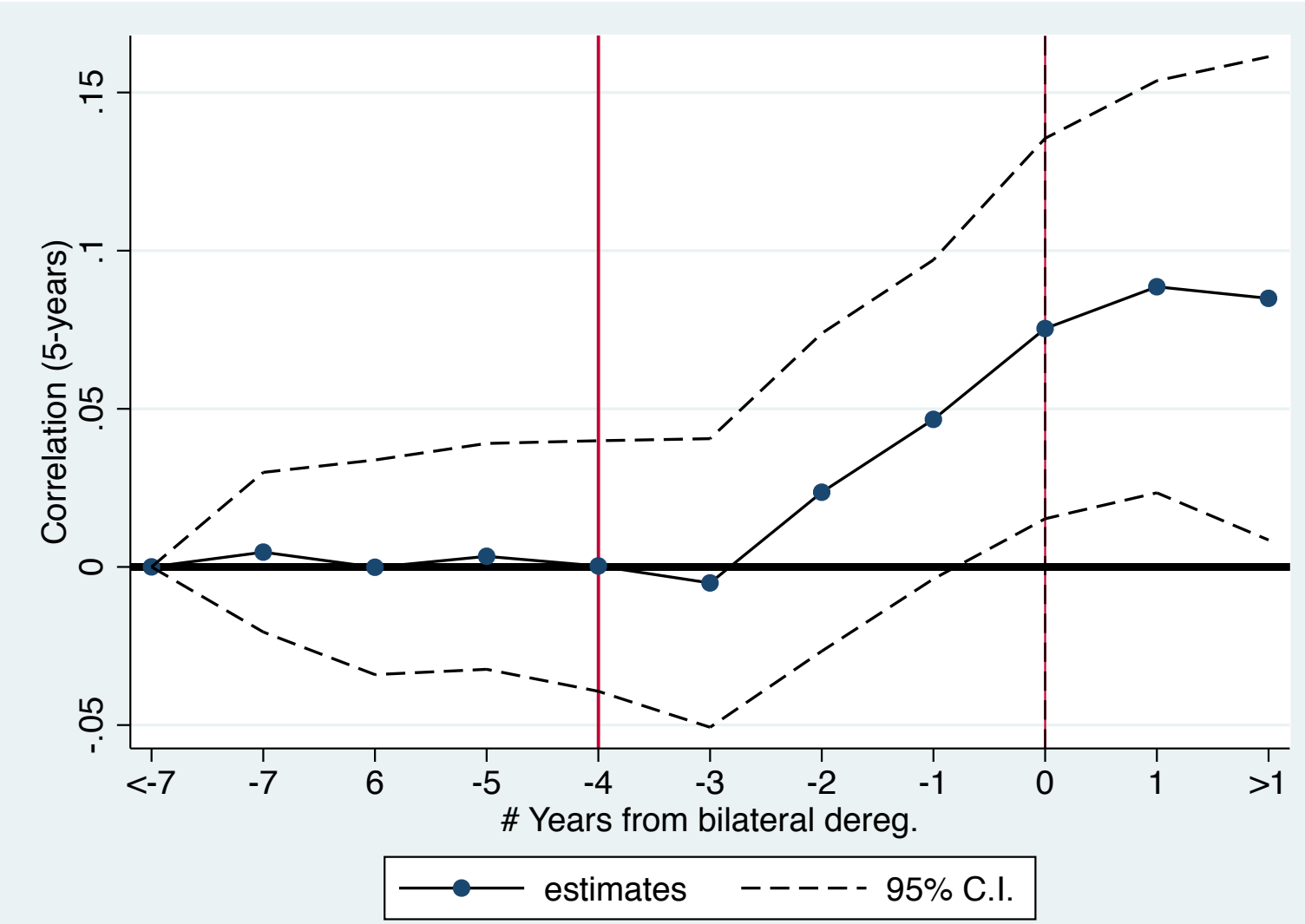

Figure 4: Real Estate Price Correlation and Interstate Banking Deregulation: Regression Results

Source: OFHEO real estate price index. Note: This figure plots the coefficient estimates (and the corresponding confidence interval) for the $\beta_{k}$ coefficients in the reduced-form regression: $\rho_{i j}^{t}=\sum_{k=-7}^{1} \beta_{k} \mathbb{1}_{t=T_{i j}+k}+\beta_{>2} \mathbb{1}_{t \geq T_{i j}+2}+\alpha_{i j}+\delta_{t}+\mu_{i t}+\nu_{j t}+\beta X_{i j}^{t}+\epsilon_{i j}^{t}$ where $\rho_{i j}^{t}$ is the 5year forward correlation of real estate price growth in state-pair $(i, j), T_{i j}$ is the year of bilateral deregulation of interstate banking for state-pair $i j, X$ contains $\log ($ Income 1), $\log ($ Income 2), Differences in industry composition and Income Correlation, as defined in Table I. 


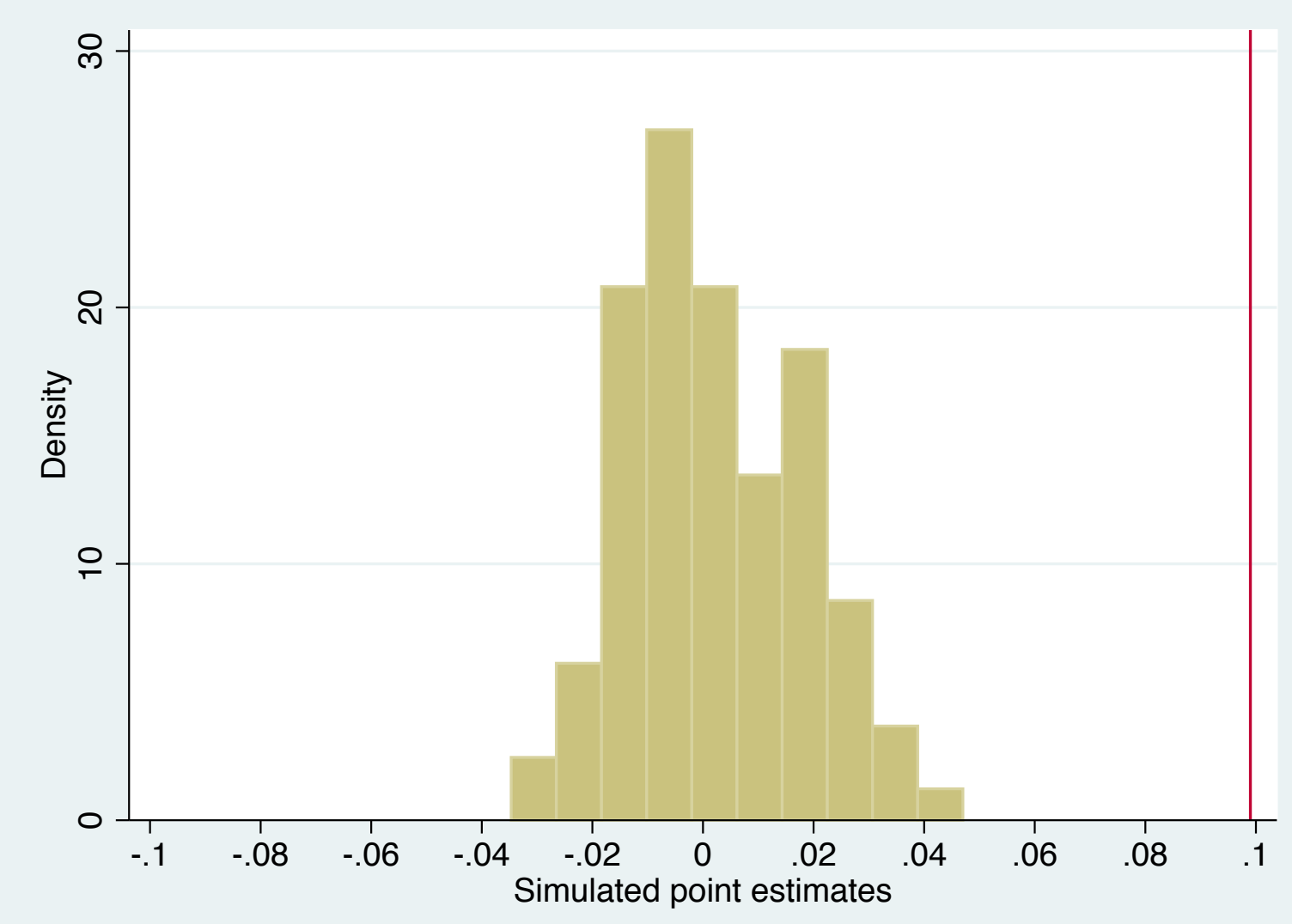

Figure 5: Empirical Distribution of Placebo Estimates

Note: This figure reports the empirical distribution of the point estimates recovered in these placebo regressions. We randomly draw deregulation dates with replacement from the empirical distribution of deregulation dates. We then re-run the analysis of column 3, Table $\mathrm{V}$ on these placebo deregulations. We repeat this procedure 100 times. 

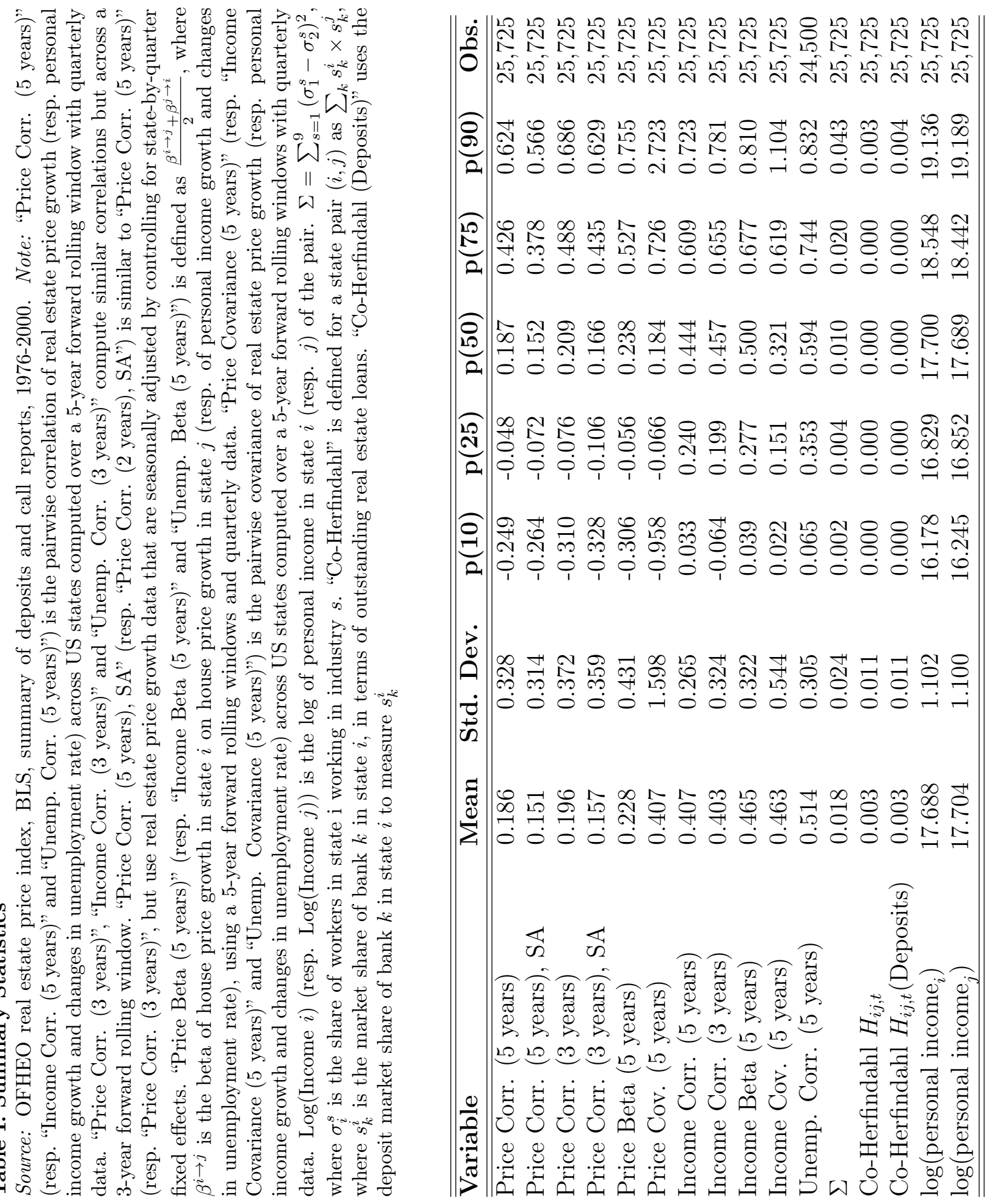


\section{Table II: Evolution of Bank Integration}

Source: FDIC summary of deposits and call reports, 1976-1996. Note: This Table reports the evolution of the average "Co-Herfindahl," defined for a state pair $(i, j)$ as $\sum_{k} s_{i, t}^{k} \times s_{j, t}^{k}$, where $s_{i, t}^{k}$ is the market share of bank $k$ in state $i$ in year $t$. Column (1) to (3) use real estate lending market shares, computed from call reports; Column (4) to (6) use deposit market shares, computed from FDIC summary of deposits data. For each state pair, the co-Herfindahl is decomposed into two parts. The first one is the contribution of the 20 largest BHCs by total assets, namely $\sum_{k^{\prime}} s_{i, t}^{k^{\prime}} \times s_{j, t}^{k^{\prime}}$, where $k^{\prime}$ are BHCs who belong to the top 20 by total assets nationwide. The second component is the residual, that is, the contribution of all other banks. Column (1) and (4) reports the average co-Herfindahl by period, across state-pair-years in the period. Column (2) and (5) do the same with the top 20 contribution. Column (3) and (6) do the same with the residual.

\begin{tabular}{lcccccc}
\hline \hline & $\begin{array}{c}\text { All BHCs } \\
\text { Lending } H_{i j}\end{array}$ & Top 20 & All BHCs & Top 20 & Others \\
Deposit $H_{i j}$ & \\
\hline \hline $1976-1980$ & .0016 & .0015 & .00013 & .0014 & .0014 & .000075 \\
$1981-1985$ & .0016 & .0011 & .0005 & .0016 & .0014 & .00014 \\
$1986-1990$ & .0021 & .0012 & .0009 & .0025 & .0017 & .00085 \\
$1991-1995$ & .0046 & .0036 & .00093 & .0049 & .004 & .00089 \\
$1996-2000$ & .0045 & .0038 & .00075 & .01 & .0093 & .00075 \\
\hline \hline
\end{tabular}


Table III: Internal Capital Markets and Lending Comovement Across States: BHC-Level Evidence Source: Call reports. Sample period: 1976-1996 unless otherwise noted. Note: The data is quarterly. The dependent variable is Loan growth $b, s, t$, the loan growth realized by BHC $b$ in state $s$. The main RHS variable is Loan growth ${ }_{b, s^{\prime}, t}$, the growth of loans made by members of the same BHC $b$ in other states $s^{\prime}$. Loan growth $b^{\prime}, s, t$ is a control for local lending shocks: the growth of loans made other BHCs $b^{\prime}$ in the same state $s$. Standard errors are clustered at the state level. T-statistics reported in parentheses. All regressions include year fixed effects; Columns (3) and (7) contain state-date fixed effects. ${ }^{*}, * *$, and ${ }^{* * *}$ mean statistically different from zero at $10 \%, 5 \%$ and $1 \%$ significance levels.

\begin{tabular}{lccccccc}
\hline \hline Sample Period & All years & All years & All years & $1976-1991$ & $1992-1995$ & All years & All years \\
& $(1)$ & $(2)$ & $(3)$ & $(4)$ & $(5)$ & $(6)$ & $(7)$ \\
\hline Loan growth $_{b, s^{\prime}, t}$ & $.095^{* * *}$ & $.095^{* * *}$ & $.07^{* * *}$ & $.087^{* * *}$ & $.1^{* * *}$ & $.088^{* * *}$ & $.057^{* * *}$ \\
& $(6.9)$ & $(7)$ & $(4.6)$ & $(5)$ & $(6)$ & $(4.9)$ & $(2.9)$ \\
$1_{t \leq 1991} \times$ Loan growth $_{b, s^{\prime}, t}$ & & & & & & .015 & .025 \\
& & & & & & $(.65)$ & $(1)$ \\
Loan growth & & .029 & & .074 & -.0016 & .029 & \\
& & $(1.1)$ & & $(1.5)$ & $(-.051)$ & $(1.1)$ & \\
Observations & 22,050 & 22,050 & 22,050 & 10,971 & 11,079 & 22,050 & 22,050 \\
R-squared & .016 & .016 & .17 & .022 & .0096 & .016 & .17 \\
Date FE & $\mathrm{Y}$ & $\mathrm{Y}$ & $\mathrm{N}$ & $\mathrm{Y}$ & $\mathrm{Y}$ & $\mathrm{Y}$ & $\mathrm{N}$ \\
State-date FE & $\mathrm{N}$ & $\mathrm{N}$ & $\mathrm{Y}$ & $\mathrm{N}$ & $\mathrm{N}$ & $\mathrm{N}$ & $\mathrm{Y}$ \\
\hline
\end{tabular}




\section{Table IV: Bank Integration and Banking Deregulation}

Note: Sample period: 1976-1996. The dependent variable is the 5-year forward rolling average of the co-Herfindahl index $H_{i j, t}^{m}$. In Panel A, $H_{i j, t}^{m}$ is computed using real estate lending market shares; in Panel $\mathrm{B}$, it is computed using deposits market shares. After Deregulation is the 5-year forward rolling average of a dummy variable equal to 1 in the years following the bilateral deregulation of interstate banking. $\frac{t-(T-4)}{5} \times \mathbb{1}_{T-4 \leq t \leq T}$ is a variable equal to $\frac{t-\left(T^{i, j}-4\right)}{5}$ for years $t \in\left[T^{i, j}-4, T^{i, j}\right]$, where $T^{i, j}$ is the deregulation year for state-pair $(i j)$. $\mathbb{1}_{t \geq T+1}$ is a dummy equal to 1 in the years following deregulation for state-pair $(i j) . \mathbb{1}_{T-3 \leq t \leq T}$ is a dummy equal to 1 for years $t$ such that $t \in\left[T^{i, j}-3, T^{i, j}\right]$. $\log \left(\right.$ personal income $_{i}$ ) is the log of the 5-year moving average of state i's personal income. Income Correlation is the pairwise correlation of personal income growthacross US states computed every year over a 5 -year rolling windows using quarterly data. $\Sigma=\sum_{s=1}^{9}\left(\sigma_{1}^{s}-\sigma_{2}^{s}\right)^{2}$, where $\sigma_{i}^{s}$ measures the share of workers in state i working in industry $s$. All specifications include year fixed effects. Column (3)-(8) include state-pair fixed effects. Columns (4)-(8) include state $i$-by-year fixed effects and state $j$-by-year fixed effects. Column (5) excludes observations $t \in\left[T^{i, j}-3, T^{i, j}\right]$. Columns (8) restricts the sample period to 1976-1990. Standard errors are two-way clustered at the state $i$ and state $j$ level. T-statistics are reported in parentheses. ${ }^{*},{ }^{* *}$, and ${ }^{* * *}$ mean statistically different from zero at $10 \%, 5 \%$ and $1 \%$ significance levels. 
Table V (Continued):

\begin{tabular}{|c|c|c|c|c|c|c|c|c|}
\hline & (1) & (2) & 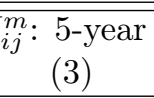 & $\begin{array}{l}\text { olling win } \\
\text { (4) }\end{array}$ & $\begin{array}{c}\text { ow co-Her } \\
(5)\end{array}$ & $\begin{array}{c}\text { ndahl inde } \\
(6)\end{array}$ & $(7)$ & (8) \\
\hline \multicolumn{9}{|c|}{ Panel A: Lending Co-Herfindhal } \\
\hline After Deregulation & $\begin{array}{c}.0095^{* * *} \\
(4.9)\end{array}$ & $\begin{array}{c}.0094^{* * *} \\
(4.9)\end{array}$ & $\begin{array}{c}.0039 * * * \\
(5.1)\end{array}$ & $\begin{array}{c}.0057^{* * *} \\
(4.5)\end{array}$ & $\begin{array}{c}.0061^{* * * *} \\
(4.7)\end{array}$ & & & $\begin{array}{c}.0072^{* * *} \\
(5.2)\end{array}$ \\
\hline$\frac{t-(T-4)}{5} \times \mathbb{1}_{T-4 \leq t \leq T}$ & & & & & & $\begin{array}{c}.0015^{* *} \\
(2.1)\end{array}$ & & \\
\hline $\mathbb{1}_{t \geq T+1}$ & & & & & & $\begin{array}{c}.0064^{* * *} \\
(4.7)\end{array}$ & $\begin{array}{c}.0057^{* * *} \\
(4.4)\end{array}$ & \\
\hline $\mathbb{1}_{T-3 \leq t \leq T}$ & & & & & & & $\begin{array}{c}.000047 \\
(.14)\end{array}$ & \\
\hline $\log \left(\right.$ personal income $\left._{i}\right)$ & & $\begin{array}{c}-.00055 \\
(-1.3)\end{array}$ & $\begin{array}{c}.0041^{*} \\
(1.7)\end{array}$ & & & & & \\
\hline $\log \left(\right.$ personal income $_{)} j$ & & $\begin{array}{c}-.00038 \\
(-1)\end{array}$ & $\begin{array}{c}.0086^{* *} \\
(2.6)\end{array}$ & & & & & \\
\hline$\Sigma$ & & $\begin{array}{l}.0016 \\
(.17)\end{array}$ & $\begin{array}{l}.05^{*} \\
(1.7)\end{array}$ & $\begin{array}{l}.072^{*} \\
(2)\end{array}$ & $\begin{array}{l}.1^{* *} \\
(2.6)\end{array}$ & $\begin{array}{l}.067^{*} \\
(1.9)\end{array}$ & $\begin{array}{l}.067^{*} \\
(1.9)\end{array}$ & $\begin{array}{l}.048 \\
(1.5)\end{array}$ \\
\hline Income Correlation & & $\begin{array}{c}.0041^{* * * *} \\
(3.4)\end{array}$ & $\begin{array}{c}.00049 \\
(.95)\end{array}$ & $\begin{array}{c}-.00013 \\
(-.2)\end{array}$ & $\begin{array}{c}-.00023 \\
(-.32)\end{array}$ & $\begin{array}{c}-.00024 \\
(-.38)\end{array}$ & $\begin{array}{c}-.00024 \\
(-.39)\end{array}$ & $\begin{array}{c}-.00053 \\
(-1)\end{array}$ \\
\hline Observations & 25,725 & 25,725 & 25,725 & 25,683 & 20,758 & 25,683 & 25,683 & 18,345 \\
\hline$R^{2}$ & 0.08 & 0.10 & 0.77 & 0.80 & 0.82 & 0.81 & 0.81 & 0.89 \\
\hline
\end{tabular}

Panel B: Deposits Co-Herfindhal

After Deregulation

$\frac{t-(T-4)}{5} \times \mathbb{1}_{T-4 \leq t \leq T}$

$\mathbb{1}_{t \geq T+1}$

$\mathbb{1}_{T-3 \leq t \leq T}$

$\log \left(\right.$ personal income $_{i}$ )

$\log \left(\right.$ personal $_{\text {income }}$ )

$\Sigma$

Income Correlation

Observations

$R^{2}$

Year FE

State-pair FE

State $i \times$ Year FE

State $j \times$ Year FE $\begin{array}{ccccc}.011^{* * *} & .011^{* * *} & .0037^{* * *} & .0056^{* * *} & .006^{* * *}\end{array}$

(4.9)

(4.9)

(3.9)

(3.9)

.00059

(.73) $.0065^{* * *} \quad .0059^{* * *}$

(4.1) (3.8)

$-.00035$

$(-.76)$
$.0091^{* * *}$

(5.1)

$-.0004 \quad .0093^{* * *}$

$(-.87) \quad(3)$

$-.00015 \quad .012^{* * *}$

$(-.38) \quad(2.8)$

$.013 \quad .073^{*}$

(1.3) (2)

$.0049^{* * *} \quad .00065^{*}$

(1.7)

$.14^{* * *}$

$.18^{* * *}$

$.13^{* *}$

$.13^{* *}$

(2.6)

(3.2)

$-.00024$

$-.0003$

(2.6)

$-.00037$

$-.00038$

(-.64)

$.083^{* *}$

(2.2)

$-.00062$

(4)

$(-.39)$

$(-.41)$

(-.62)

$(-1.1)$

25,725

25,725

25,725

25,683

20,758

25,683

25,683

18,345

0.12

0.76

$\begin{array}{ll}0.80 & 0.82\end{array}$

0.81

0.81

0.89

\begin{tabular}{|c|c|c|c|c|c|c|c|}
\hline Yes & Yes & Yes & Yes & Yes & Yes & Yes & Yes \\
\hline No & No & Yes & Yes & Yes & Yes & Yes & Yes \\
\hline No & No & No & Yes & Yes & Yes & Yes & Yes \\
\hline No & No & No & Yes & Yes & Yes & Yes & Yes \\
\hline
\end{tabular}




\section{Table V: House Price Correlation and Banking Deregulation}

Note: Sample period: 1976-1996. The dependent variable is the pairwise correlation of house price growth across US states, defined using a 5-year forward rolling window using quarterly data. In Panel A, house price growth is not seasonally adjusted. In Panel B, house price growth is seasonally adjusted by projecting quarterly house price growth on state-by-quarter dummies. After Deregulation is the 5-year forward rolling average of a dummy variable equal to 1 in the years following the bilateral deregulation of interstate banking. $\frac{t-(T-4)}{5} \times \mathbb{1}_{T-4 \leq t \leq T}$ is a variable equal to $\frac{t-\left(T^{i, j}-4\right)}{5}$ for years $t \in\left[T^{i, j}-4, T^{i, j}\right]$, where $T^{i, j}$ is the deregulation year for state-pair $(i j)$. $\mathbb{1}_{t \geq T+1}$ is a dummy equal to 1 in the years following deregulation for state-pair $(i j)$. $\mathbb{1}_{T-3 \leq t \leq T}$ is a dummy equal to 1 for years $t$ such that $t \in\left[T^{i, j}-3, T^{i, j}\right] . \log \left(\right.$ personal income ${ }_{i}$ ) is the $\log$ of the 5 -year moving average of state i's personal income. Income Correlation is the pairwise correlation of personal income growth across US states computed every year over a 5-year rolling windows using quarterly data. $\Sigma=\sum_{s=1}^{9}\left(\sigma_{1}^{s}-\sigma_{2}^{s}\right)^{2}$, where $\sigma_{i}^{s}$ measures the share of workers in state i working in industry $s$. All specifications include year fixed effects. Column (3)-(8) include state-pair fixed effects. Columns (4)-(8) include state $i$-by-year fixed effects and state $j$-by-year fixed effects. Column (5) excludes observations $t \in\left[T^{i, j}-3, T^{i, j}\right]$. Columns (8) restricts the sample period to 1976-1990. Standard errors are two-way clustered at the state $i$ and state $j$ level. T-statistics are reported in parentheses. ${ }^{*},{ }^{* *}$, and ${ }^{* * *}$ mean statistically different from zero at $10 \%, 5 \%$ and $1 \%$ significance levels. 
Table V (Continued):

\begin{tabular}{|c|c|c|c|c|c|c|c|c|}
\hline & \multicolumn{8}{|c|}{$\rho_{i j}: 5$-year rolling window house price correlation } \\
\hline & (1) & $(2)$ & $(3)$ & $(4)$ & $(5)$ & $(6)$ & $(7)$ & $(8)$ \\
\hline \multicolumn{9}{|c|}{ Panel A: Unadjusted House Price Growth } \\
\hline After Deregulation & $\begin{array}{l}.074^{* *} \\
(2.4)\end{array}$ & $\begin{array}{c}.065^{* *} \\
(2.5)\end{array}$ & $\begin{array}{c}.057^{* *} \\
(2.2)\end{array}$ & $\begin{array}{c}.096^{* * *} \\
(3.6)\end{array}$ & $\begin{array}{c}.08^{* * * *} \\
(3.3)\end{array}$ & & & $\begin{array}{c}.11^{* * *} \\
(3.9)\end{array}$ \\
\hline$\frac{t-(T-4)}{5} \times \mathbb{1}_{T-4 \leq t \leq T}$ & & & & & & $\begin{array}{c}.092^{* * *} \\
(3.3)\end{array}$ & & \\
\hline $\mathbb{1}_{t \geq T+1}$ & & & & & & $\begin{array}{c}.097^{* * *} \\
(3.6)\end{array}$ & $\begin{array}{c}.078^{* * *} \\
(3)\end{array}$ & \\
\hline $\mathbb{1}_{T-3 \leq t \leq T}$ & & & & & & & $\begin{array}{c}.031^{* *} \\
(2)\end{array}$ & \\
\hline $\log \left(\right.$ personal income $\left._{i}\right)$ & & $\begin{array}{c}.031^{* * *} \\
(4.9)\end{array}$ & $\begin{array}{l}.2^{*} \\
(1.7)\end{array}$ & & & & & \\
\hline $\log \left(\right.$ personal income $\left.{ }_{j}\right)$ & & $\begin{array}{c}.025^{* *} \\
(2.2)\end{array}$ & $\begin{array}{l}.27^{*} \\
(2)\end{array}$ & & & & & \\
\hline$\Sigma$ & & $\begin{array}{l}-.28 \\
(-1.2)\end{array}$ & $\begin{array}{l}.98 \\
(.97)\end{array}$ & $\begin{array}{l}-.38 \\
(-.22)\end{array}$ & $\begin{array}{l}.28 \\
(.18)\end{array}$ & $\begin{array}{l}-.38 \\
(-.22)\end{array}$ & $\begin{array}{l}-.38 \\
(-.22)\end{array}$ & $\begin{array}{c}7.6^{* * *} \\
(3.2)\end{array}$ \\
\hline Income Correlation & & $\begin{array}{l}.16^{* * *} \\
(5.3)\end{array}$ & $\begin{array}{l}.051^{*} \\
(1.8)\end{array}$ & $\begin{array}{c}.066^{* *} \\
(2.1)\end{array}$ & $\begin{array}{l}.076^{* *} \\
(2.3)\end{array}$ & $\begin{array}{c}.066^{* *} \\
(2.1)\end{array}$ & $\begin{array}{l}.066^{* *} \\
(2.1)\end{array}$ & $\begin{array}{l}.11^{* * *} \\
(2.9)\end{array}$ \\
\hline Observations & 25,725 & 25,725 & 25,725 & 25,683 & 20,758 & 25,683 & 25,683 & 18,345 \\
\hline$R^{2}$ & 0.12 & 0.16 & 0.39 & 0.53 & 0.54 & 0.53 & 0.53 & 0.52 \\
\hline \multicolumn{9}{|c|}{ Panel B: Seasonally-adjusted House Price Growth } \\
\hline After Deregulation & $\begin{array}{c}.066^{* * *} \\
(2.7)\end{array}$ & $\begin{array}{c}.059^{* * *} \\
(2.8)\end{array}$ & $\begin{array}{l}.05^{* *} \\
(2.4)\end{array}$ & $\begin{array}{c}.074^{* * *} \\
(2.9)\end{array}$ & $\begin{array}{c}.063^{* *} \\
(2.6)\end{array}$ & & & $\begin{array}{c}.088^{* * *} \\
(3)\end{array}$ \\
\hline$\frac{t-(T-4)}{5} \times \mathbb{1}_{T-4 \leq t \leq T}$ & & & & & & $\begin{array}{c}.084^{* * *} \\
(3)\end{array}$ & & \\
\hline $\mathbb{1}_{t \geq T+1}$ & & & & & & $\begin{array}{c}.073^{* * *} \\
(2.8)\end{array}$ & $\begin{array}{l}.058^{* *} \\
(2.3)\end{array}$ & \\
\hline $\mathbb{1}_{T-3 \leq t \leq T}$ & & & & & & & $\begin{array}{l}.031^{*} \\
(1.9)\end{array}$ & \\
\hline $\log \left(\right.$ personal income $\left._{i}\right)$ & & $\begin{array}{c}.027^{* * *} \\
(3.9)\end{array}$ & $\begin{array}{l}.16^{*} \\
(1.8)\end{array}$ & & & & & \\
\hline $\log \left(\right.$ personal income $\left._{j}\right)$ & & $\begin{array}{c}.025^{* *} \\
(2.4)\end{array}$ & $\begin{array}{l}.24^{* *} \\
(2.4)\end{array}$ & & & & & \\
\hline$\Sigma$ & & $\begin{array}{l}-.062 \\
(-.25)\end{array}$ & $\begin{array}{l}.99 \\
(1.1)\end{array}$ & $\begin{array}{l}-.03 \\
(-.017)\end{array}$ & $\begin{array}{l}.54 \\
(.31)\end{array}$ & $\begin{array}{l}-.02 \\
(-.011)\end{array}$ & $\begin{array}{l}-.016 \\
(-.0093)\end{array}$ & $\begin{array}{c}7.6^{* * *} \\
(3.2)\end{array}$ \\
\hline Income Correlation & & $\begin{array}{c}.15^{* * *} \\
(4.7)\end{array}$ & $\begin{array}{c}.056^{* *} \\
(2.4)\end{array}$ & $\begin{array}{c}.078^{* * *} \\
(2.8)\end{array}$ & $\begin{array}{l}.074^{* *} \\
(2.5)\end{array}$ & $\begin{array}{c}.078^{* * *} \\
(2.8)\end{array}$ & $\begin{array}{c}.078^{* * *} \\
(2.8)\end{array}$ & $\begin{array}{c}.11^{* * *} \\
(3)\end{array}$ \\
\hline Observations & 25,725 & 25,725 & 25,725 & 25,683 & 20,758 & 25,683 & 25,683 & 18,345 \\
\hline$R^{2}$ & 0.08 & 0.11 & 0.38 & 0.52 & 0.52 & 0.52 & 0.51 & 0.52 \\
\hline Year FE & Yes & Yes & Yes & Yes & Yes & Yes & Yes & Yes \\
\hline State-pair FE & No & No & Yes & Yes & Yes & Yes & Yes & Yes \\
\hline State $i \times$ Year FE & No & No & No & Yes & Yes & Yes & Yes & Yes \\
\hline State $j \times$ Year FE & No & No & No & Yes & Yes & Yes & Yes & Yes \\
\hline
\end{tabular}




\section{Table VI: House Price Correlation and Banking Deregulation: Robustness Checks}

Note: Sample period: 1976-1996. The dependent variable is the pairwise correlation of house price growth across US states, defined using a 5-year forward rolling window using quarterly data. In Panel A, house price growth is not seasonally adjusted. In Panel B, house price growth is seasonally adjusted by projecting quarterly house price growth on state-by-quarter dummies. After Deregulation is the 5-year forward rolling average of a dummy variable equal to 1 in the years following the bilateral deregulation of interstate banking. After First Deregulation is the 5-year moving average of a dummy variable equal to 1 in the years following the first deregulation of interstate banking across the two states in the pair. Income (resp. Unemp.) Correlation is the pairwise correlation of personal income growth (resp. change in unemployment rates) across US states computed every quarter over a 5-year rolling windows using quarterly data. Income beta is the average beta of income growth (resp. change in unemployment rate) of state $i$ on income growth of state $j$, computed over a 5 -year rolling window using quarterly data, averaged over the pairs $(i, j)$ and $(j, i) . \Sigma=\sum_{s=1}^{9}\left(\sigma_{1}^{s}-\sigma_{2}^{s}\right)^{2}$ where $\sigma_{i}^{s}$ measures the share of workers in state i working in industry i. All specifications include state-pair fixed effects as well as state-year fixed effects for each state in the pair. Column (1) excludes the state-pairs with bilateral reciprocal deregulations. Column (2) adds state-pair specific trend to the specific in Column (4) of Table V. Column (3) only includes a window of 5 years around the bilateral deregulation of interstate banking in the state-pair. Column (4) explicitly controls for the behavior of price growth correlation in the years following the first deregulation of interstate banking in the state-pair. Column (5) uses a 3-year rolling window to compute all the variables. Column (6) does not control for income correlation. Column (7) adds the correlation in changes in unemployment rates as a control variable. Column (8) uses as a dependent variable the average beta of real estate price growth of state $i$ on real estate price growth of state $j$, computed over a 5-year rolling windows using quarterly data, averaged over the pairs $(i, j)$ and $(j, i)$. Column (9) uses as a dependent variable the covariance of real estate price growth of state-pairs, computed over a 5-year rolling window using quarterly data. Standard errors are two-way clustered at the state $i$ and state $j$ level. T-statistics reported in parentheses. ${ }^{*},{ }^{* *}$, and ${ }^{* * *}$ mean statistically different from zero at $10 \%, 5 \%$ and $1 \%$ significance levels. 
Table VI (Continued):

\begin{tabular}{|c|c|c|c|c|c|c|c|c|c|}
\hline & $(1)$ & $(2)$ & $\begin{array}{l}\rho_{i j}: \text { Ho } \\
(3)\end{array}$ & $\begin{array}{l}\text { ise price } \\
(4)\end{array}$ & $\begin{array}{c}\text { orrelation } \\
(5)\end{array}$ & $(6)$ & $(7)$ & $\begin{array}{c}\text { Beta } \\
(8)\end{array}$ & $\begin{array}{l}\text { Cov. } \\
(9)\end{array}$ \\
\hline \multicolumn{10}{|c|}{ Panel A: Unadjusted House Price Growth } \\
\hline After Deregulation & $\begin{array}{c}.18^{* * *} \\
(7.1)\end{array}$ & $\begin{array}{l}.1^{* * *} \\
(3.6)\end{array}$ & $\begin{array}{c}.16^{* * *} \\
(5.1)\end{array}$ & $\begin{array}{l}.1^{* * *} \\
(5.2)\end{array}$ & $\begin{array}{c}.078^{* * *} \\
(3.2)\end{array}$ & $\begin{array}{c}.097 * * * \\
(3.7)\end{array}$ & $\begin{array}{c}.092^{* * *} \\
(3.5)\end{array}$ & $\begin{array}{c}.083^{* *} \\
(2.4)\end{array}$ & $\begin{array}{l}.21^{* *} \\
(2.5)\end{array}$ \\
\hline After First Deregulation & & & & $\begin{array}{c}-.0066 \\
(-.23)\end{array}$ & & & & & \\
\hline$\Sigma$ & $\begin{array}{c}-2.2 * * \\
(-2.5)\end{array}$ & $\begin{array}{c}19 * * * \\
(3.3)\end{array}$ & $\begin{array}{c}-23^{* * *} \\
(-4.3)\end{array}$ & $\begin{array}{l}-.37 \\
(-.21)\end{array}$ & $\begin{array}{l}-.58 \\
(-.59)\end{array}$ & $\begin{array}{l}-.16 \\
(-.093)\end{array}$ & $\begin{array}{l}-.99 \\
(-.53)\end{array}$ & $\begin{array}{l}-.29 \\
(-.14)\end{array}$ & $\begin{array}{l}-1.1 \\
(-.16)\end{array}$ \\
\hline Income Correlation & $\begin{array}{l}.0076 \\
(.26)\end{array}$ & $\begin{array}{c}.08^{* * *} \\
(2.7)\end{array}$ & $\begin{array}{l}.017 \\
(.43)\end{array}$ & $\begin{array}{c}.066^{* *} \\
(2.1)\end{array}$ & $\begin{array}{l}.0027 \\
(.18)\end{array}$ & & $\begin{array}{c}.069^{* *} \\
(2.1)\end{array}$ & & \\
\hline Unemp. Correlation & & & & & & & $\begin{array}{l}-.057 \\
(-1.4)\end{array}$ & & \\
\hline Income Beta & & & & & & & & $\begin{array}{c}.071^{* *} \\
(2.6)\end{array}$ & \\
\hline Income Covariance & & & & & & & & & $\begin{array}{c}.07 \\
(1.7)\end{array}$ \\
\hline Observations & 21,882 & 25,683 & 11,057 & 25,683 & 28,129 & 25,683 & 24,460 & 25,683 & 25,683 \\
\hline$R^{2}$ & 0.31 & 0.73 & 0.74 & 0.53 & 0.49 & 0.53 & 0.54 & 0.48 & 0.41 \\
\hline \multicolumn{10}{|c|}{ Panel B: Seasonally-Adjusted House Price Growth } \\
\hline After Deregulation & $\begin{array}{c}.13^{* * * *} \\
(6.2)\end{array}$ & $\begin{array}{c}.097^{* * *} \\
(3.6)\end{array}$ & $\begin{array}{c}.15^{* * * *} \\
(5.2)\end{array}$ & $\begin{array}{c}.076^{* * *} \\
(3.2)\end{array}$ & $\begin{array}{c}.077^{* * *} \\
(2.9)\end{array}$ & $\begin{array}{c}.075^{* * *} \\
(2.9)\end{array}$ & $\begin{array}{c}.072^{* * *} \\
(2.8)\end{array}$ & $\begin{array}{l}.051 \\
(1.5)\end{array}$ & $\begin{array}{l}.21^{* *} \\
(2.3)\end{array}$ \\
\hline After First Deregulation & & & & $\begin{array}{l}-.0022 \\
(-.084)\end{array}$ & & & & & \\
\hline$\Sigma$ & $\begin{array}{c}-.99 \\
(-1.4)\end{array}$ & $\begin{array}{c}18^{* * *} \\
(3.5)\end{array}$ & $\begin{array}{c}-22^{* * *} \\
(-4.2)\end{array}$ & $\begin{array}{l}-.029 \\
(-.016)\end{array}$ & $\begin{array}{c}-.0072 \\
(-.0062)\end{array}$ & $\begin{array}{c}.12 \\
(.072)\end{array}$ & $\begin{array}{c}-.67 \\
(-.35)\end{array}$ & $\begin{array}{c}.012 \\
(.0057)\end{array}$ & $\begin{array}{l}-1.3 \\
(-.17)\end{array}$ \\
\hline Income Correlation & $\begin{array}{l}.033 \\
(1.4)\end{array}$ & $\begin{array}{c}.08^{* * *} \\
(3.1)\end{array}$ & $\begin{array}{l}.017 \\
(.44)\end{array}$ & $\begin{array}{c}.078^{* * *} \\
(2.8)\end{array}$ & $\begin{array}{l}.014 \\
(1.2)\end{array}$ & & $\begin{array}{c}.079^{* * *} \\
(2.8)\end{array}$ & & \\
\hline Unemp. Correlation & & & & & & & $\begin{array}{l}.006 \\
(.25)\end{array}$ & & \\
\hline Income Beta & & & & & & & & $\begin{array}{c}.09^{* * *} \\
(3.4)\end{array}$ & \\
\hline Income Covariance & & & & & & & & & $\begin{array}{l}.077 \\
(1.6)\end{array}$ \\
\hline Observations & 21,882 & 25,683 & 11,057 & 25,683 & 28,129 & 25,683 & 24,460 & 25,683 & 25,683 \\
\hline$R^{2}$ & 0.33 & 0.71 & 0.73 & 0.52 & 0.47 & 0.51 & 0.53 & 0.46 & 0.42 \\
\hline State-pair FE & Yes & Yes & Yes & Yes & Yes & Yes & Yes & Yes & Yes \\
\hline State $i \times$ Year FE & No & Yes & Yes & Yes & Yes & Yes & Yes & Yes & Yes \\
\hline State $j \times$ Year FE & No & Yes & Yes & Yes & Yes & Yes & Yes & Yes & Yes \\
\hline State-pair FE $\times$ Year Trend & No & Yes & No & No & No & No & No & No & No \\
\hline
\end{tabular}




\section{Table VII: House Price Correlation and Banking Integration: OLS and IV Estimation}

Source: OFHEO house price index and call reports. Sample period: 1976-1996 (Columns (1)-(3) and (7)-(9)), and 19761990 (Columns (4)-(6) and (10)-(12)). Note: The dependent variable is the 5-year forward rolling correlation of house price growth. In Panel A, house price growth is not seasonally adjusted. In Panel B, house price growth is seasonally adjusted by projecting quarterly house price growth on state-by-quarter dummies. $H_{i j, t}^{m}$ is the co-Herfindhal index. In Columns (1)-(6), $H_{i j, t}^{m}$ is computed using real estate lending market shares; in Columns (7)-(12), it is computed using deposits market shares. $H_{i j, t}^{m} . \Sigma=\sum_{s=1}^{9}\left(\sigma_{1}^{s}-\sigma_{2}^{s}\right)^{2}$, where $\sigma_{i}^{s}$ measures the share of workers in state $i$ working in industry $s$. We then take the 5-year forward rolling average of this measure. Income Correlation is the pairwise correlation of personal income growth across US states computed every quarter over a 5-year rolling window using quarterly data. All specifications include year, state-pair, and state-year fixed effects. Column (1), (4), (7), (10) provide OLS estimation. Columns (2), (5), (8) and (11) provide IV estimation where a state pair's co-Herfindahl is instrumented using the specification in Column (6) of Table IV. Columns (3), (6), (9) and (12) use the specification of Column (5) of Table IV to instrument for $H_{i j}^{m}$. Standard errors are two-way clustered at the state $i$ and state $j$ level. T-statistics reported in parentheses. ${ }^{*}, * *$, and $* * *$ mean statistically different from zero at $10 \%, 5 \%$ and $1 \%$ significance levels. 


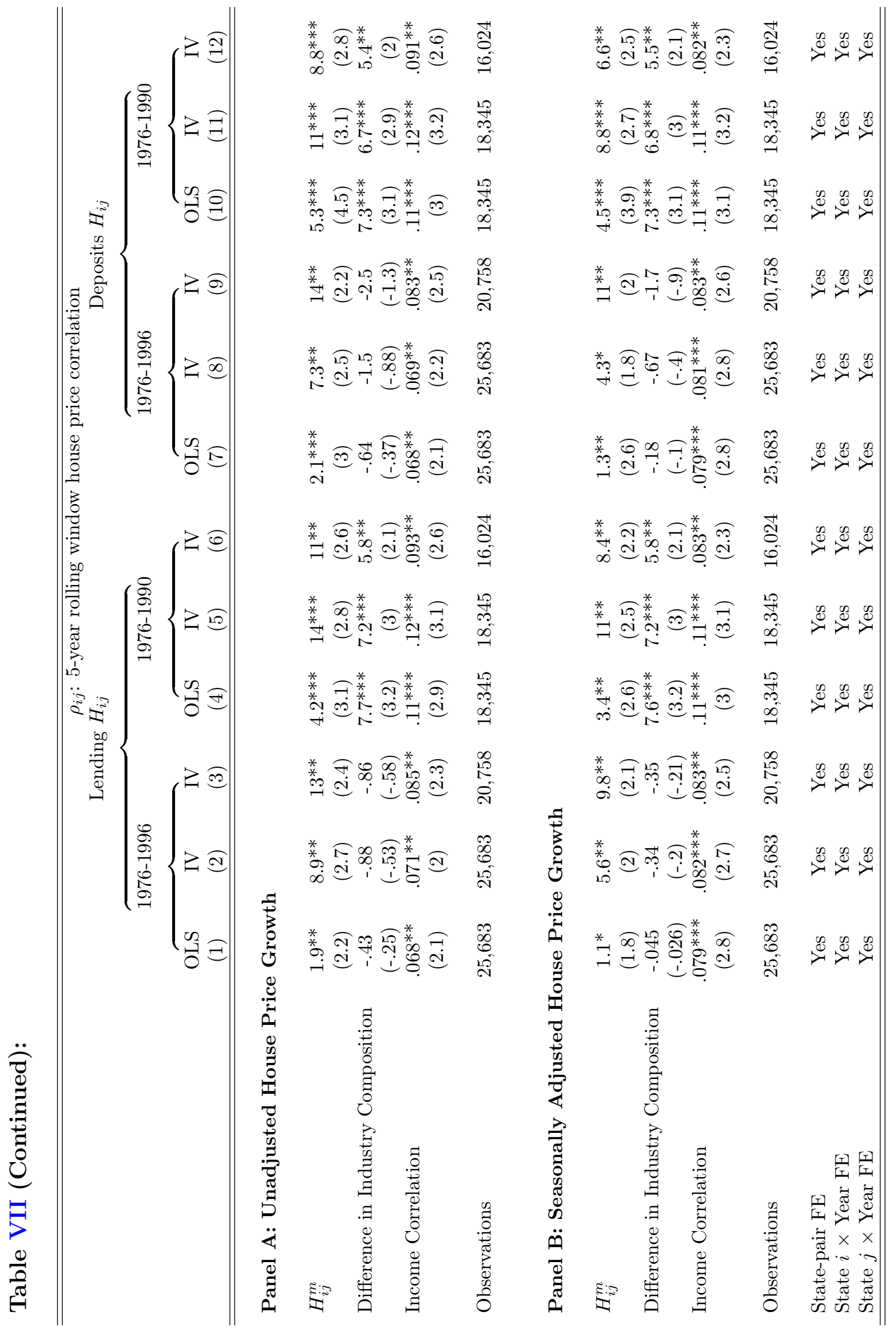




\section{APPENDIX}

\section{A. Bank size and Shock Volatility}

In this appendix, we explain how heteroskedastic idiosyncratic lending shocks affect our calculations and estimates. The issue is the following: if larger banks have smaller idiosyncratic shocks, their effect on comovement should be smaller than in our baseline model. We first expose this effect theoretically, and use the derivation to account for the fact that bank size is negatively correlated with volatility. We show that this adjustment does not affect our results significantly.

To see how the link between bank size and volatility affects our derivations, let us assume the bank-specific idiosyncratic shock is a decreasing function of bank size: $f\left(L_{t-1}^{k}\right) \eta_{k}$ instead of $\eta_{k} . f$ is a decreasing function. The rest of the correlation structure is the same as in the baseline model. In this new model, the volatility of bank shocks is thus given by $\sigma_{\eta} . f\left(L_{t-1}^{k}\right)$.

The covariance equation (3) becomes

$$
\operatorname{cov}\left(\frac{\Delta P_{i, t}}{P_{i, t-1}}, \frac{\Delta P_{j, t}}{P_{j, t-1}}\right)=\rho_{\epsilon} \sigma_{\epsilon}^{2}+\mu^{2} \sigma_{a}^{2}+\mu^{2} \sigma_{\eta}^{2} \sum_{1}^{K}\left(f\left(L_{t-1}^{k}\right)\right)^{2}\left(\frac{L_{i, t-1}^{k}}{L_{i, t-1}} \cdot \frac{L_{j, t-1}^{k}}{L_{j, t-1}}\right) .
$$

The new determinant of comovement is the sum of local market share products of overlapping banks, weighted by a decreasing function of bank size. Hence, overlapping banks contribute less to comovement if they are big, because big banks are less volatile. Hence, the size-volatility relationship affects the way we measure bank integration, all the more so when $f$ is more sensitive to bank size.

To find out about function $f$, we regress the volatility of loan growth on the log of bank size. We split our sample into four five-year periods: 1980-1984, 1985-1989, 1990-1994 and 1995-1999. For each of these periods, we restrict ourselves to BHCs continuously present in the call reports for all 20 quarters. Within each of these periods, and for each of these banks, 
we then calculate the standard deviation of quarterly loan growth using all 20 quarters, and the log of total loans at the first quarter of the period. We then regress loan growth volatility -normalized by $4.2 \%$, which is the average volatility - on-beginning-of period log bank assets. In doing so, we assume $f(x)=a+b \log (x)$, and $\sigma_{\eta}=4.2 \%$.

We find that, indeed, larger banks are slightly less volatile than small ones, but that the sensitivity is small. We report in Figure A.1 scatter plots for each of the four sub-periods, using total assets as our loan measure. The sensitivity of volatility to size is present, but decreasing over time. To analyze significance, we report regression results in Table A.I. Across all subperiods, the largest (negative) value for coefficient $b$ is -0.3 , which means that multiplying bank size by 1000 reduces volatility by $\log (1000) \times 0.3 \approx .3 .8$ percentage points. Thus, the correction for the bank-size effect is a priori unlikely to have major effects on our results.

However, we check this prediction formally. We take the estimated size-volatility relation, and recalculate the new integration measure $K_{i j}$ using the formula suggested by the previous equation:

$$
K_{i j}=\sum_{1}^{K}\left(a-b \log \left(L_{t-1}^{k}\right)\right)^{2}\left(\frac{L_{i, t-1}^{k}}{L_{i, t-1}} \cdot \frac{L_{j, t-1}^{k}}{L_{j, t-1}}\right)
$$

where $a$ and $b$ are estimated on the pooled panel of BHCs used in Table A.I, separately for measures using total assets and real estate loans only. Running this pooled regression, we find $a=2.98$ and $b=0.232$, which we plug in the above formula. These numbers are consistent with those of Table A.I.

We then explore the correlation between this adjusted measure $K_{i j}$ and the integration measure $H_{i j}$ that we use in the main text. We show a scatter plot in Figure A.2. Note first that, in contrast to $H_{i j}$, the adjusted $K_{i j}$ does not have to mechanically be between 0 and 1 . But more importantly, both measures are highly correlated, with a linear correlation of .78. Thus, because volatility is not very sensitive to bank size, the measure of bank integration that we use in the main text is a good proxy for the size-adjusted measure.

As a final robustness check, we re-estimate the relationship between correlation and 
integration with the new integration measure. We re-estimate the results reported in Table VII, except we use $K_{i j}$ instead of $H_{i j}$ as our main explanatory variable. As we do for $H_{i j}$, we compute the five-year forward rolling average of $K_{i j}$ to account for the fact that correlation is itself estimated on a five-year forward rolling window (see Section 4.1). We use the same instruments as in the main text (bilateral banking deregulations), and run regressions using both 1976-2000 and 1976-1994 samples. As in Table VII, we report both OLS and IV estimates in Table A.II. We find the estimates have the same level of statistical significance and similar economic sizes. This finding suggests the simplifying approximation that bank volatility does not depend on size - an approximation we make in the text - is correct. 

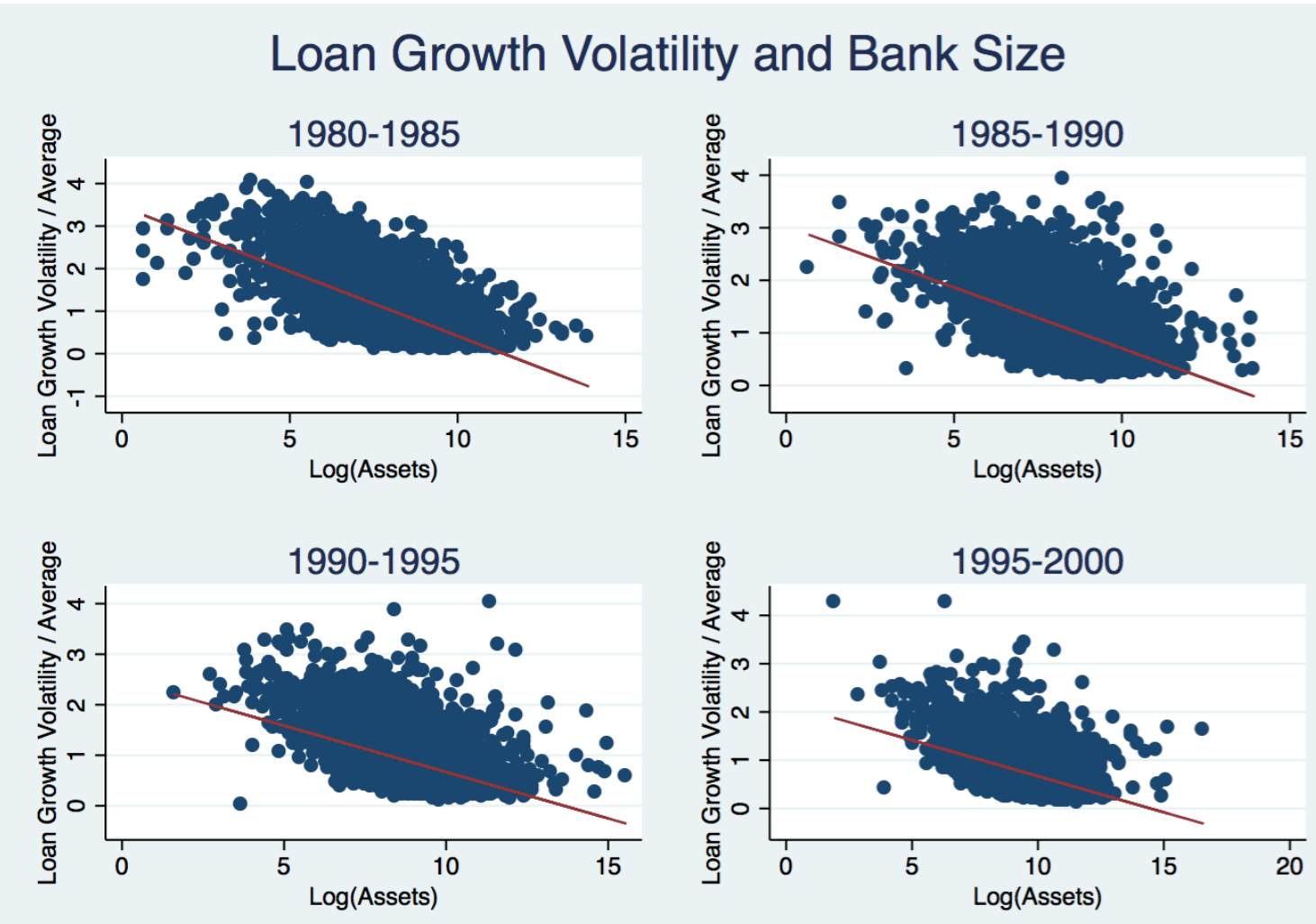

Note: 4 Cross-Sections; Each Dot is a Bank

Figure A.1: Bank Size and Bank Volatility - Scatter Plots

Source: call reports. Note: We first split our sample into 4 subperiods. Within each of these periods, we focus on the balanced panel of banks that report loan figures in the Call Reports for each of the 20 quarters. Then we calculate, for each bank, the log of real estate loans at the first quarter of the period, and the standard deviation of quarterly home loan growth over the period. We then plot the second variable against the first one, for each subperiod separately. The red line is the fitted univariate regressions. Regression results corresponding to these plots are reported in Table A.I. 


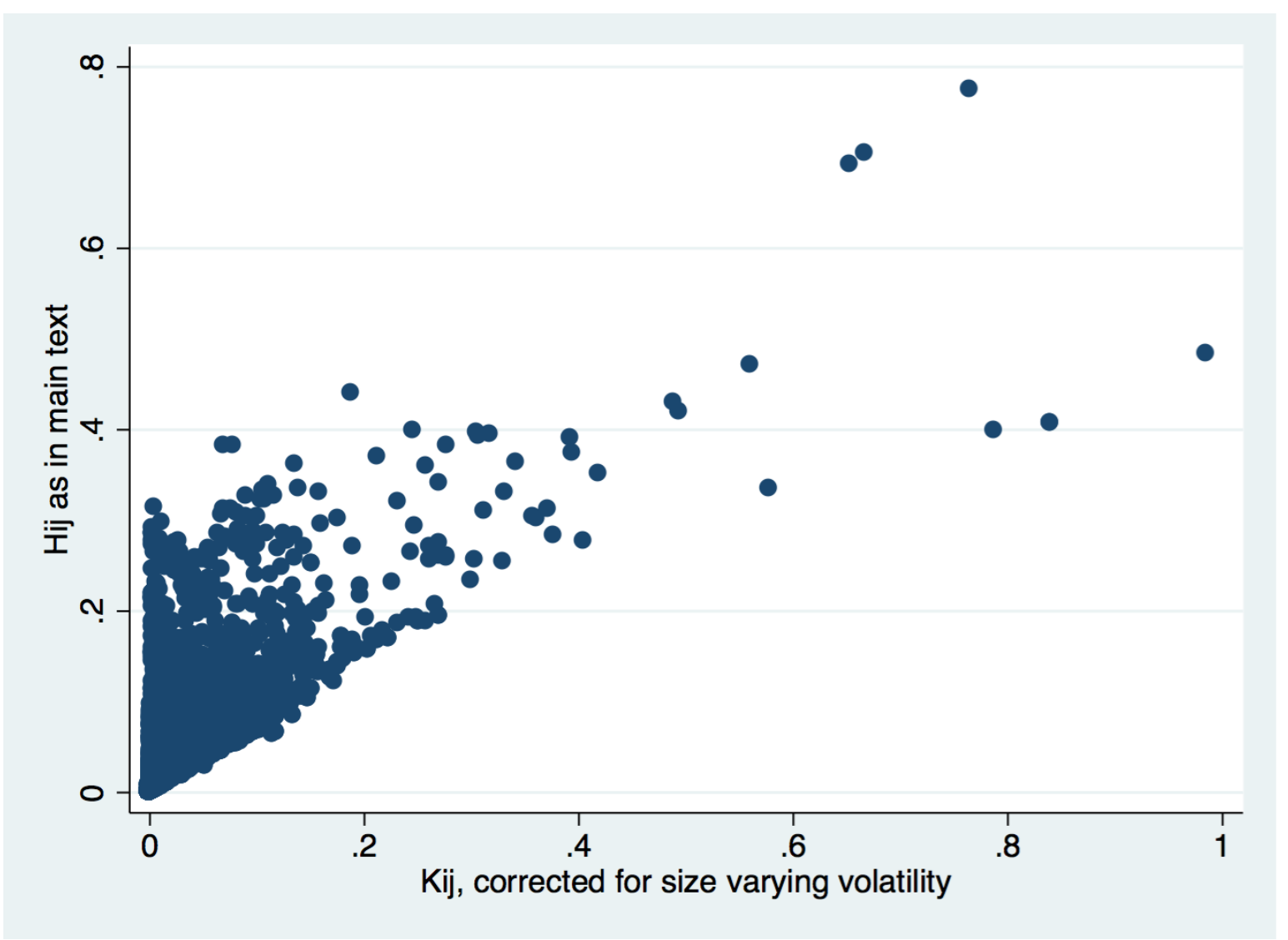

Figure A.2: Measuring Integration: With and Without Bank-Size Adjustment

Source: Call reports. Note: This Figure graphically illustrates the correlation between the co-Herfindahl and the size-volatility-adjusted measure of integration. On the yaxis, we report the unadjusted overlap measure $H_{i j}$ that we use in the paper, given by: $\sum_{1}^{K}\left(\frac{L_{i, t-1}^{k}}{L_{i, t-1}} \cdot \frac{L_{j, t-1}^{k}}{L_{j, t-1}}\right)$, whereas on the x-axis, we report the bank-size-adjusted measure given by: $\sum_{1}^{K}\left(a-b \log \left(L_{t-1}^{k}\right)\right)^{2}\left(\frac{L_{i, t-1}^{k}}{L_{i, t-1}} \cdot \frac{L_{j, t-1}^{k}}{L_{j, t-1}}\right)$, where $a$ and $b$ are estimated as in Table A.I, but after pooling all sub-periods together. This alternative definition accounts for the fact that overlaps should matter less for bigger banks -which are less volatile. The univariate linear correlation is .78 . 
Table A.I: Bank Size and Bank Volatility - Regressions

Source: Call reports. Note: We first split our sample into 4 subperiods. Within each of these periods, we focus on the balanced panel of banks that report loan figures in the call reports for each of the 20 quarters. Then, we calculate, for each bank, the log of total loans at the first quarter of the period, and the standard deviation of quarterly loan growth over the period. We then report the cross-sectional regression results, separately for each sub-period. t-stats are between parentheses. ${ }^{* * *}$ means "significant at $1 \%$.

\begin{tabular}{lcccc}
\hline \hline & \multicolumn{4}{c}{ Volatility of $\frac{\Delta L_{t}^{k}}{L_{t-1}^{k}}$} \\
& $(1)$ & $(2)$ & $(3)$ & $(4)$ \\
& $1980-1984$ & $1985-1989$ & $1990-1994$ & $1995-1999$ \\
\hline $\log \left(\right.$ Loans $\left._{0}^{k}\right)$ & $-.3^{* * *}$ & $-.23^{* * *}$ & $-.18^{* * *}$ & $-.15^{* * *}$ \\
& $(-56)$ & $(-43)$ & $(-39)$ & $(-31)$ \\
Constant & $3.5^{* * *}$ & $3^{* * *}$ & $2.5^{* * *}$ & $2.2^{* * *}$ \\
& $(79)$ & $(67)$ & $(59)$ & $(48)$ \\
Observations & 4,986 & 5,099 & 5,194 & 4,172 \\
R2 & 0.39 & 0.26 & 0.23 & 0.19 \\
\hline \hline
\end{tabular}




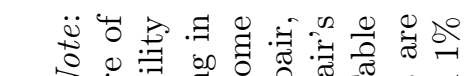

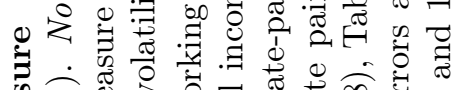

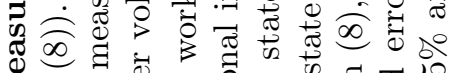

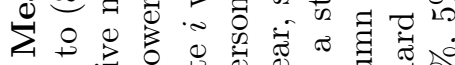

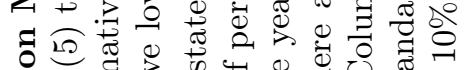

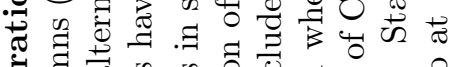
ธू。 궁

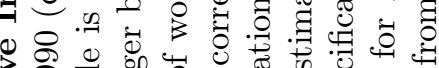

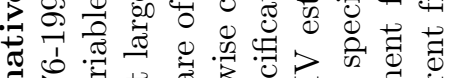

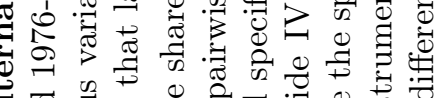

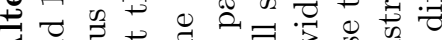

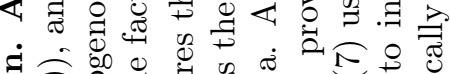

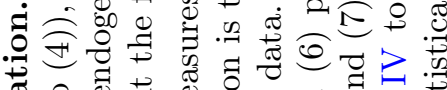

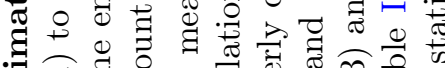

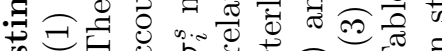
现

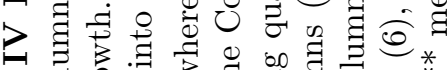
ح

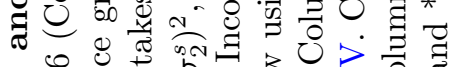

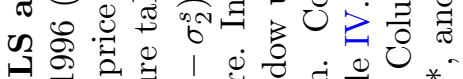

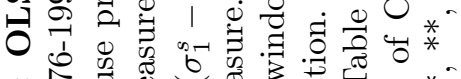
ㅂ.

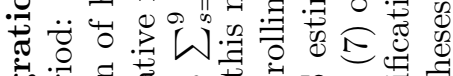

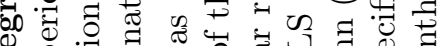

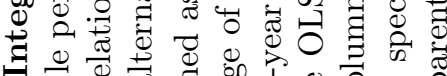

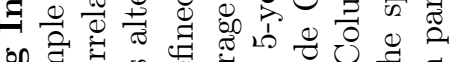
ט

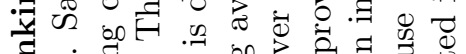
สี

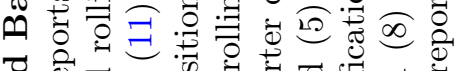

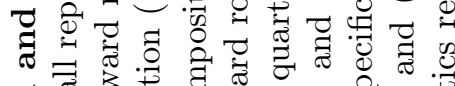
व

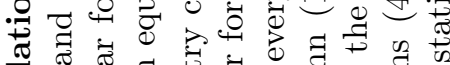

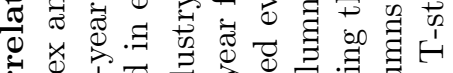

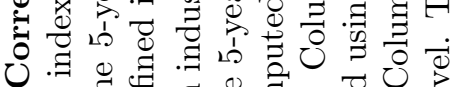

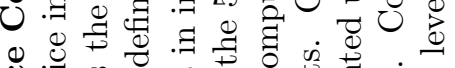

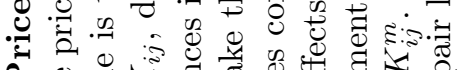
ڤ 0 क

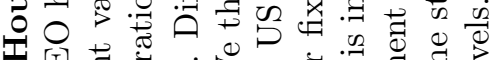

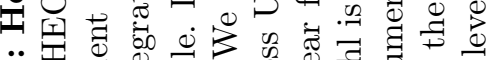

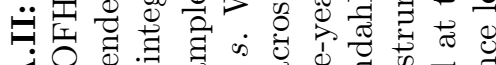

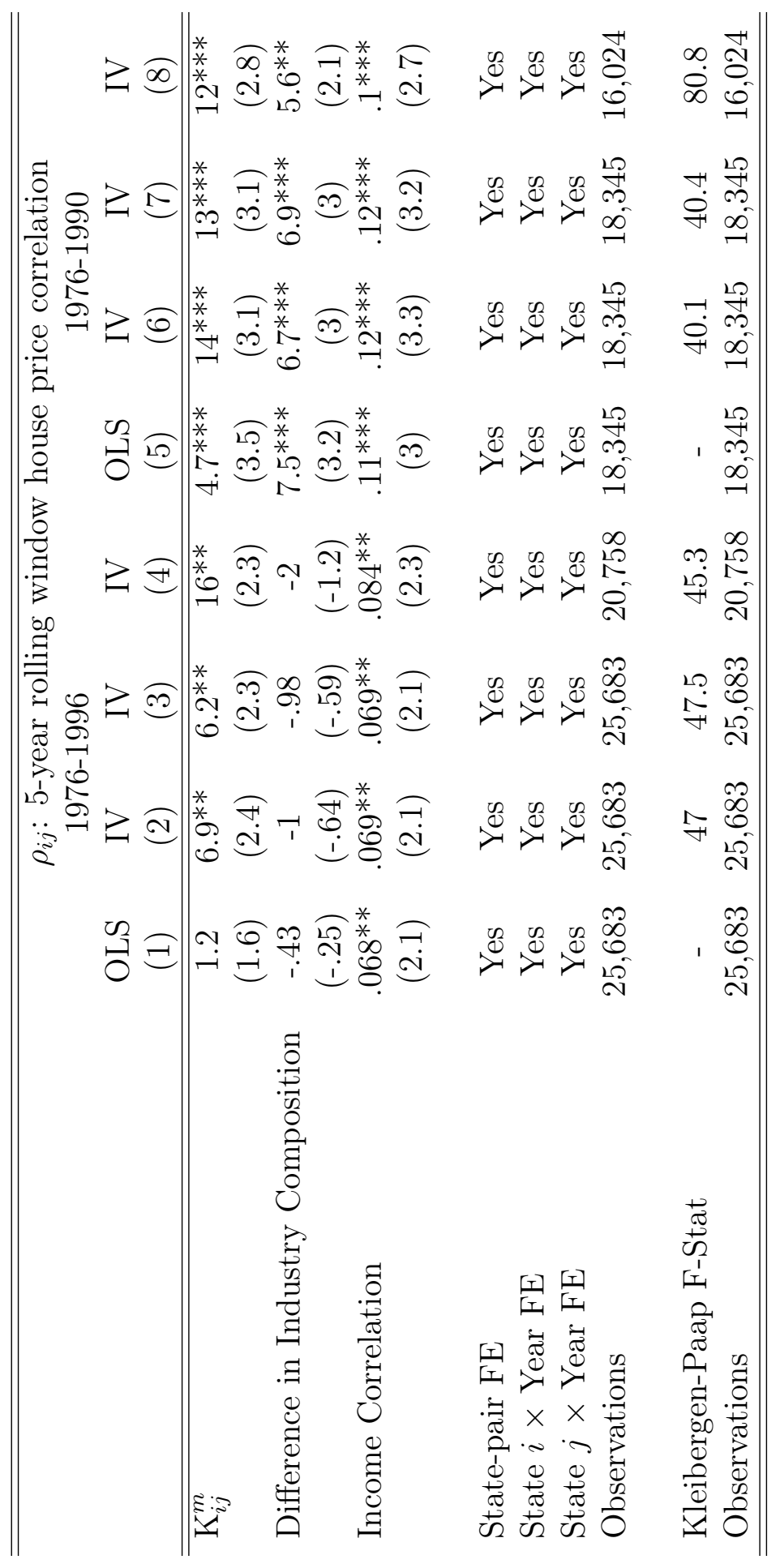
4 东

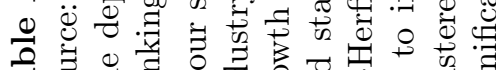

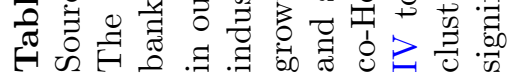




\section{B. Aggregate Bank Shocks and the Rise of House Price Correlation}

This Appendix examines the hypothesis that the rise in house price comovement is due to the increased volatility of aggregate lending shocks. This alternative explanation is not exclusive of ours, but, as we show here, it is not a plausible candidate. If anything, aggregate bank lending shocks have become less, not more, volatile over the past 30 years.

One potential explanation for the rise in house price correlation is that bank lending policies have become increasingly affected by common aggregate shocks. The rise in the reliance on wholesale funding, or on securitization of loans, may represent aggregate trends that are making banks increasingly subject to similar, aggregate, funding shocks. In this case, house price comovement might increase, not because similar banks inject their own shocks to several states, but because banks have simply become more and more "alike".

In our model, this hypothesis amounts to saying the contribution of the aggregate bank shock $\sigma_{a}$ has increased. To see this equivalence, it is useful to go back to equation (5):

$$
\operatorname{corr}\left(\frac{\Delta P_{i, t}}{P_{i, t}}, \frac{\Delta P_{j, t}}{P_{j, t}}\right)=\gamma_{1}\left(\sigma_{a}^{2}\right)+\gamma_{2}\left(\sigma_{a}^{2}\right) H_{i j}-\gamma_{3}\left(\sigma_{a}^{2}\right) \frac{H_{i i}+H_{j j}}{2}
$$

where: $\gamma_{1}(x)=\frac{\rho+\frac{\mu^{2}}{\sigma_{\epsilon}^{2}} x}{1+\frac{\mu^{2}}{\sigma_{\epsilon}^{2}} x}, \gamma_{2}(x)=\frac{\mu^{2}}{\sigma_{\epsilon}^{2}} \sigma_{\eta}^{2} \frac{1}{1+\frac{\mu^{2}}{\sigma_{\epsilon}^{2}} x}$ and $\gamma_{3}(x)=\frac{\mu^{2} \sigma_{\eta}^{2}}{\sigma_{\epsilon}^{2}} \frac{\rho+\frac{\mu^{2}}{\sigma_{\epsilon}^{2}} x}{\left(1+\frac{\mu^{2}}{\sigma_{\epsilon}^{2}} x\right)^{2}}$. Aggregate risk $\left(\sigma_{a}\right)$ thus affects price growth correlations through three distinct channels. The most obvious one - the "direct" channel - is captured by $\gamma_{1}\left(\sigma_{a}^{2}\right)$, and is independent of bank geographic interlocks and concentrations. When banks have more common volatility $\left(\sigma_{a}\right)$, prices are subject to stronger common shocks and thus correlate more $\left(\gamma_{1}\right.$ is increasing in $\left.\sigma_{a}\right)$. The two other channels involve more indirect interaction terms between market integration: their impact can be ambiguous, and so we focus on the first one, which is the most intuitive.

We go to the data and directly estimate the time-series evolution of $\sigma_{a}$, which is observable. We start from the call report described in Section 3.2, and aggregate bank assets 
at the BHC-quarter level. For each BHC, we then calculate quarterly asset growth. Every quarter, we take the cross-sectional average of $\mathrm{BHC}$ asset growths, after removing outliers -observations for which asset growth was above 100\%. This average bank asset growth is the common factor to bank lending. Finally, each quarter, we compute the 20-quarters forward rolling volatility of this factor. We report its evolution over 1976-2000 in Figure B.1. The volatility of average quarterly bank growth decreases from 1.8\% in 1976 to $0.8 \%$ in 1996 . If anything, the common factor to bank lending growth became less volatile over the period. This result implies that the direct impact of aggregate risk does not have the power to explain the rise in house price correlations over 1976-2000. 


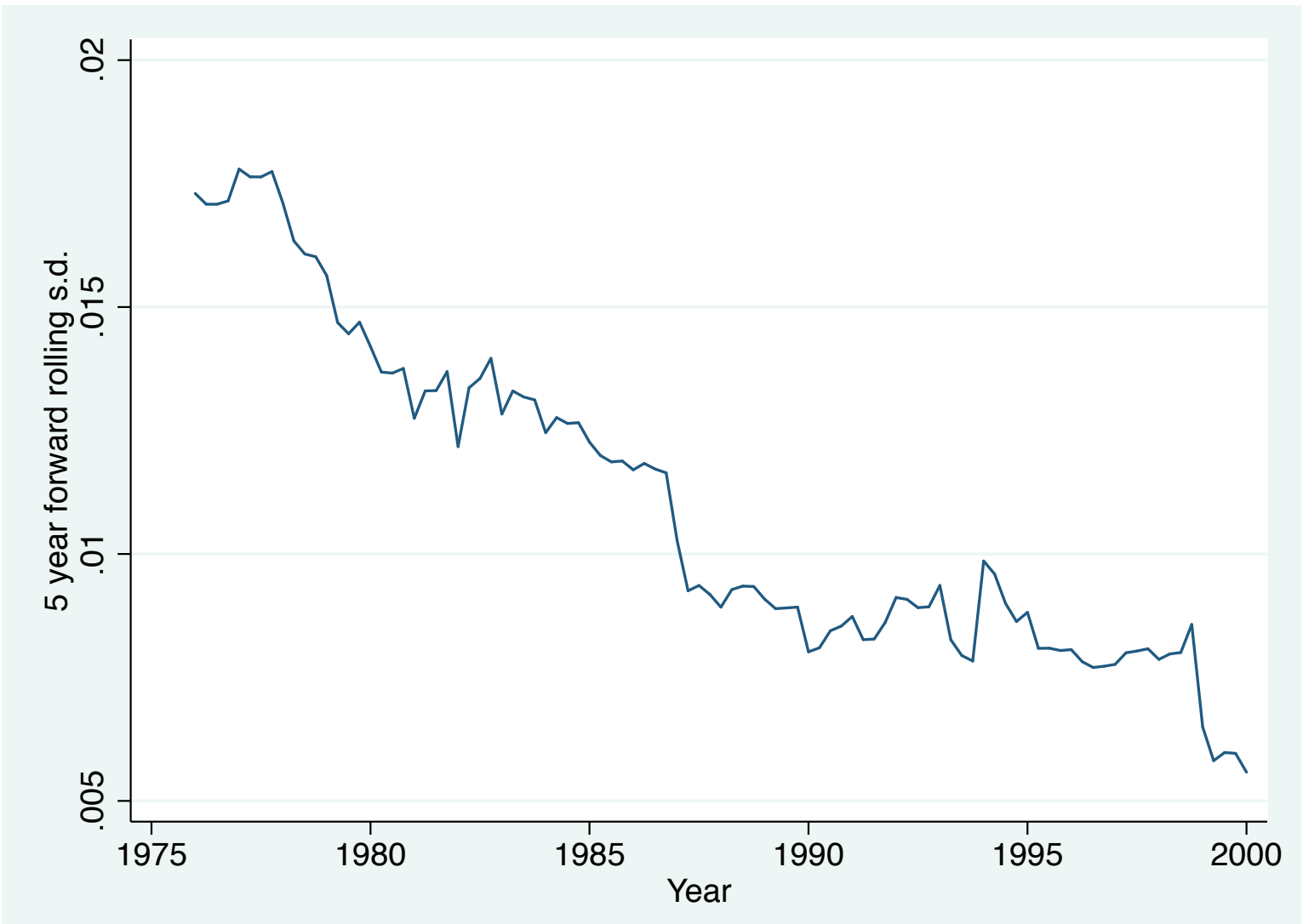

Figure B.1: The Volatility of Mean Bank Asset Growth

Source: Call reports. Note: This figure plots the rolling standard deviation of average bank lending growth. For each BHC-quarter in the call reports, we first calculate quarterly asset growth. We then remove outliers (asset growth above 100\%). We then calculate the cross-sectional equall weighted average (across BHCs). Finally, the standard deviation is computed using a 5-year forward rolling window with quarterly data. 


\section{Banking Deregulation and Income Correlation}

In this section, we show that interstate banking deregulations did not lead to an increase in income correlation. As a first test, we simply replicate our reduced-form table, Table $\mathrm{V}$, which is explained in detail in Section 4.3, but we use the 5-year forward correlation of personal income as a dependent variable. The results are shown in Table C.I. Except in Column (1), where we simply have year fixed-effects as control, the estimated $\beta$ is never significantly positive among the 8 specifications that include control variables and/or statepair fixed effects. In 3 out of the 8 specifications, the estimated effect is negative and significant, although at low significance levels (t-stat of 2.3, 1.8 and 1.9 in column (3), (4) and (9). We infer from Table C.I that interstate banking deregulations did not lead to a significant increase in personal income correlation.

We confirm this conclusion by replicating Figure 4 using again the correlation of personal income growth as a dependent variable. The results are shown in Figure C.I. This figure plots the coefficient estimates for the $\beta_{k}$ coefficients in the reduced-form regression: $\rho_{i j, t}^{\text {income }}=\sum_{k=-7}^{1} \beta_{k} \mathbb{1}_{t=T_{i j}+k}+\beta_{>1} \mathbb{1}_{t \geq T_{i j}+2}+\alpha_{i j}+\delta_{t}+\mu_{i t}+\nu_{j t}+\beta X_{i j}^{t}+\epsilon_{i j}^{t}$, where $\rho_{i j, t}^{\text {income }}$ is the 5-year forward correlation of personal income growth in state-pair $(i, j), T_{i j}$ is the year of bilateral deregulation of interstate banking for state-pair $i j$, X contains Differences

in industry composition as defined in Table I. As is evident from Figure C.I, there is no sign that interstate banking deregulations lead to an increase in personal income correlation. 


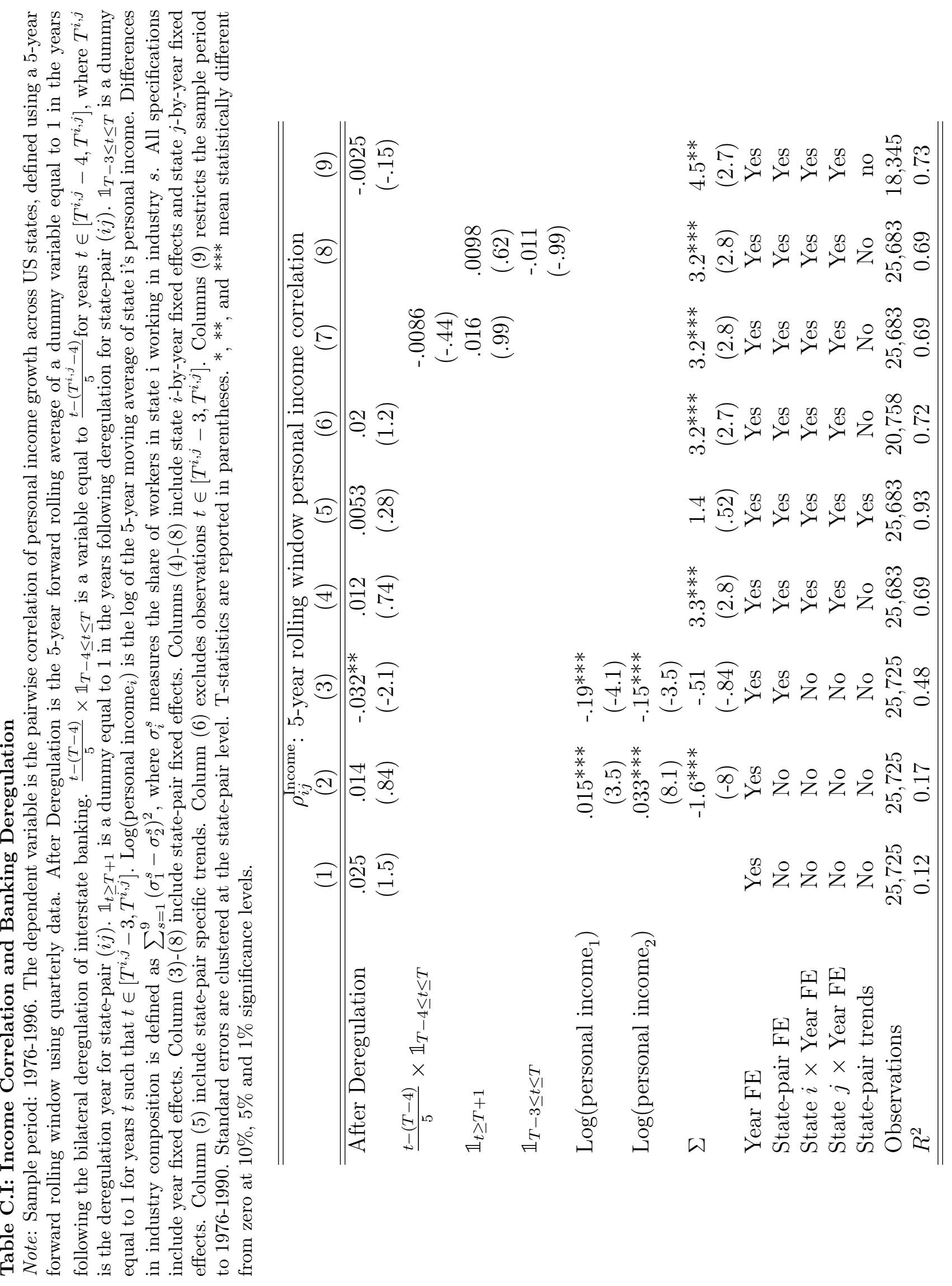




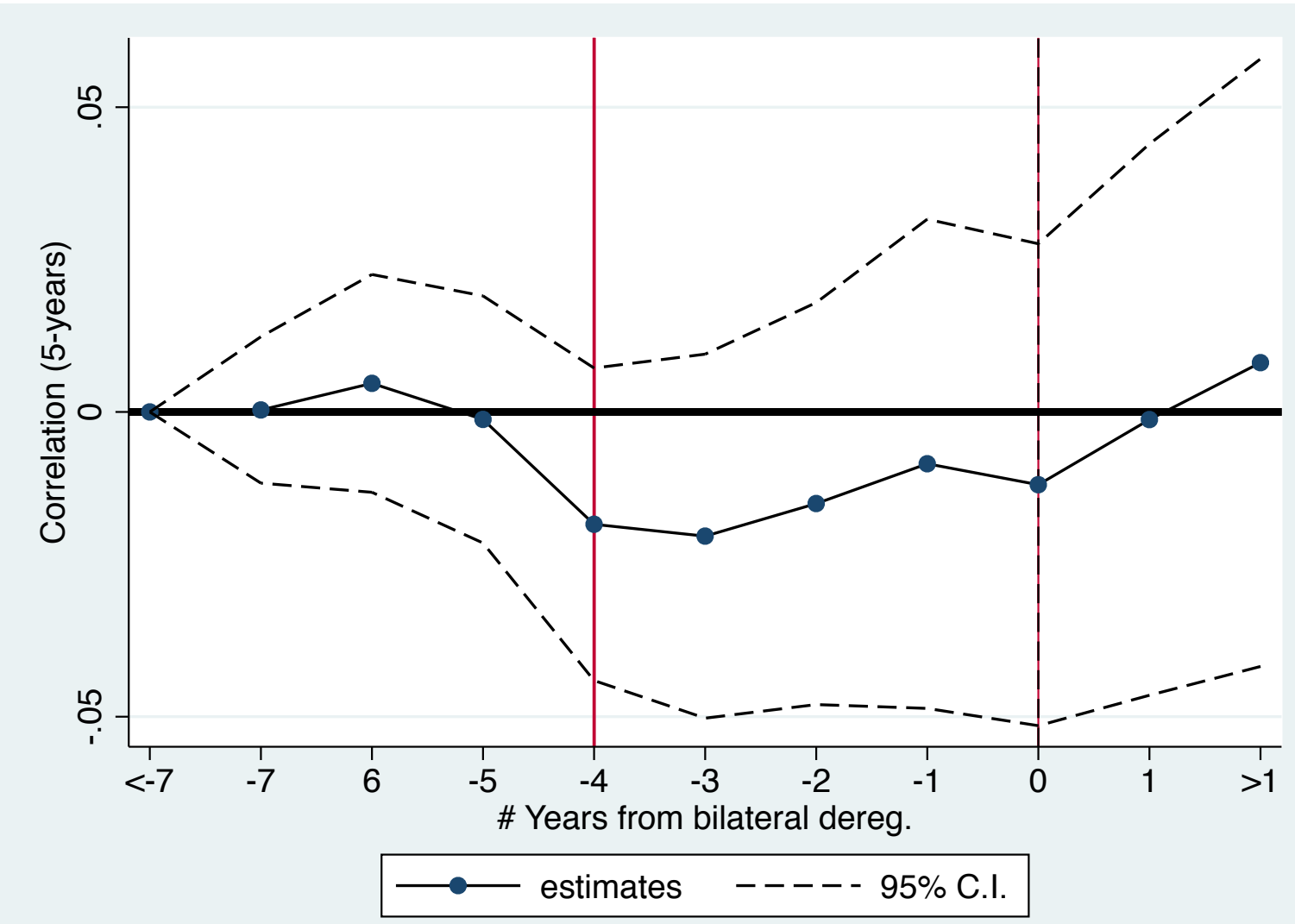

Figure C.1: Banking Deregulation and House Price Correlation: Regression Results Source: OFHEO real estate price index. Note: This figure plots the coefficient estimates (and the corresponding confidence interval) for the $\delta_{k}$ coefficients in the reduced-form regression: $\rho_{i j, t}^{\text {income }}=$ $\sum_{k=-7}^{1} \delta_{k} \mathbb{1}_{t=T_{i j}+k}+\delta_{>1} \mathbb{1}_{t \geq T_{i j}+2}+\alpha_{i j}+\delta_{t}+\mu_{i t}+\nu_{j t}+\beta X_{i j}^{t}+\epsilon_{i j}^{t}$ where $\rho_{i j, t}^{\text {income }}$ is the 5-year forward correlation of personal income growth in state-pair $(i, j), T_{i j}$ is the year of bilateral deregulation of interstate banking for state-pair $i j, \mathrm{X}$ contains Differences in industry composition as defined in Table I 